\title{
Insulation Life Span of Low-Voltage Electric Motors-A Survey
}

\author{
Vanessa Neves Höpner 1,2,*(D) and Volmir Eugênio Wilhelm ${ }^{2}$ \\ 1 Instituto Federal Catarinense, Araquari 89245-000, Santa Catarina, Brazil \\ 2 Programa de Pós-Graduação em Métodos Numéricos em Engenharia, Centro Politécnico, \\ Universidade Federal do Paraná, Curitiba 81530-900, Paraná, Brazil; volmirw@ufpr.br \\ * Correspondence: vanessa.hopner@ifc.edu.br
}

check for

updates

Citation: Höpner, V.N.; Wilhelm, V.E. Insulation Life Span of Low-Voltage Electric Motors-A Survey. Energies 2021, 14, 1738. https://doi.org/ 10.3390/en14061738

Academic Editor: Federico Barrero

Received: 18 February 2021

Accepted: 18 March 2021

Published: 21 March 2021

Publisher's Note: MDPI stays neutral with regard to jurisdictional claims in published maps and institutional affiliations.

Copyright: (c) 2021 by the authors. Licensee MDPI, Basel, Switzerland. This article is an open access article distributed under the terms and conditions of the Creative Commons Attribution (CC BY) license (https:// creativecommons.org/licenses/by/ $4.0 /)$.

\begin{abstract}
The use of static frequency converters, which have a high switching frequency, generates voltage pulses with a high rate of change over time. In combination with cable and motor impedance, this generates repetitive overvoltage at the motor terminals, influencing the occurrence of partial discharges between conductors, causing degradation of the insulation of electric motors. Understanding the effects resulting from the frequency converter-electric motor interaction is essential for developing and implementing insulation systems with characteristics that support the most diverse applications, have an operating life under economically viable conditions, and promote energy efficiency. With this objective, a search was carried out in three recognized databases. Duplicate articles were eliminated, resulting in 1069 articles, which were systematically categorized and reviewed, resulting in 481 articles discussing the causes of degradation in the insulation of electric motors powered by frequency converters. A bibliographic portfolio was built and evaluated, with 230 articles that present results on the factors that can be used in estimating the life span of electric motor insulation. In this structure, the historical evolution of the collected information, the authors who conducted the most research on the theme, and the relevance of the knowledge presented in the works were considered.
\end{abstract}

Keywords: electric motor insulation; partial discharge; dielectric breakdown

\section{Introduction}

Technological progress and cost savings of electronic switching power supply for static frequency converters allow improvements in the form of output modulated waves and generate a considerable increase in the income of low-voltage electric motors that are triggered by these widely used devices in the power sector.

The converters act as an interface between the power source (network) and the induction motor, generating thousands of voltage pulses in the motor stator winding every second with extremely short rise times. Depending on the control characteristics (gate resistors, capacitors, control voltages, etc.) and the modulation adopted, these repetitive pulses combined with the impedance of the cable and the motor can generate overvoltages at the motor terminals, reducing their operating life due to the accelerated degradation of the insulation system [1]. It is important to investigate the ability of motor insulation to withstand the stress caused by the effects of converter operation.

The prolonged heating during electrical machine operation is inevitably accompanied by thermal aging of the winding insulation system. The electric stress has been considered insignificant because the magnitude and increase of tension are much lower than the voltage of the same break for aged insulation, as well as the start voltage ionization. After an energy efficiency method to regulate the speed of electric drives based on pulse width modulation was introduced, the nature and magnitude of electric stress acting on lowvoltage winding changed $[2,3]$. Accordingly, the electrothermal characteristic became the predominant cause of aging under the action of overvoltage pulses generated by the voltage source based on the pulse width modulation (PWM) converter. 
In consideration of aspects such as manufacturing costs, maintenance, and lifetime, the electric motor insulation system becomes one of the most important components of rotating electrical machines. As the induction motor is a robust machine with simple construction, its operational context and numerous studies leave no doubt that the insulation system of a low-voltage electrical machines is the weakest element in terms of reliability [4], and its useful life depends almost exclusively on the useful life of the stator winding insulation, which is affected by many factors, such as humidity, vibration, corrosive environments, and thermal and mechanical stress, among others [5].

Advances in the quality of varnishes used in insulation have considerably improved the thermal, mechanical, and dielectric characteristics, so the standard induction motor operating at low voltage is generally capable of withstanding the voltage waveform found in most inverters. However, the type of abnormal electric stress that the insulation is subjected to when a repetitive impulse voltage wave with overshoot that can exceed 2.5 times the direct current voltage on the inverter bus is applied is greater relative to the distribution of the sinusoidal voltage, mainly in the first turns (or the last, depending on the winding design) [6]. As a result, the increase in local voltage may be sufficient for stress to occur in the electric field, initiating the partial discharge (PD) activity that causes deterioration of the wire insulation [7].

Form wound stators fail through dielectric loss-induced heating, rapid deterioration of stress control coatings, and partial discharge [8]. Partial discharges are low-energy discharges that, if they act continuously, cause erosion, resulting in a decrease in the thickness of the insulating material and causing progressive losses of dielectric properties, until the breaking voltage reaches a level below the peak level of the applied voltage.

The objective of the paper is to make a survey of articles that discuss the causes of degradation in the insulation of electric motors powered by frequency converters. The construction and evaluation of a bibliographic portfolio will also be carried out with scientific articles that present relevant results and information indicating the main factors used in estimating the life span of electric motor insulation. With the knowledge acquired, it will be possible to promote a reduction in manufacturing costs by eliminating unnecessary conservatism and the use of scientific methods to assess the reliability of motor design, in addition to promoting energy efficiency. In this structure, the historical evolution of the information collected was examined, the groups of authors who researched the most about the theme and the relevance of the knowledge presented in the works, for low-voltage electric motors and random winding.

\section{Review Methodology}

In this section, the methodology adopted in screening and selecting articles for systematic review and constructing the bibliographic portfolio is described in detail. The section is divided into subsections to better explain the selection process.

\subsection{Search Terms}

After defining the theme determining the research, it is necessary to stipulate the search terms used in the databases of the selected repositories in order to obtain relevant scientific articles. This may not be a simple task, since it establishes which articles will be selected for entry in the process and which will be excluded.

The search terms and operators used in this work were: "electric AND motor * AND insulation AND (inverter OR converter)", contained in the metadata, which includes abstract, index terms, and bibliographic citation data (such as document title, publication title, author, etc.). The asterisk $\left(^{*}\right)$ made it possible to search for both singular and plural forms of the word "motor". The words "invert" and "convert" were used because both represent the inverter or frequency converter. As a filter, only articles published in conference proceedings, journals, and magazines were selected. 


\subsection{Databases}

The databases used were chosen by the researcher because they were more consistent with the research theme. In the case that a researcher is unable to determine the best databases to consider for the research theme, a search can be carried out with search terms in several databases in order to verify which ones are more representative of the theme, that is, which ones have more scientific articles available in the area of interest. Databases were selected from three repositories: Scopus (Elsevier), IEEE Xplore, and Web of Science (WoS) (Clarivate), which were accessed on 20 October 2020.

\subsection{Exclusion of Duplicates}

When a search for articles is carried out on several bases, it is common for the set of articles gathered by the researcher to contain repeats. Initially, articles were excluded from each database separately by reading their titles. With this filtering, it was possible to observe that a typo during indexing could duplicate the article, so a thorough check was carried out. In addition, the same article can be both presented at a conference and published in a journal or magazine, which doubles its occurrence, and this comparison was made to exclude such articles. Another exclusion step was to perform a cross-check between the databases, identifying which articles appeared in only one of the three, in two, and in all three databases simultaneously.

\subsection{Thematic Relevance}

At this stage, the titles and abstracts were read, making it possible to assess whether articles were aligned with the research theme to indicate whether it would remain in or be excluded from the previous bibliographic portfolio defining its thematic relevance.

A basic question was asked: Does the article indicate in the title or summary that factors influencing the life span and causes of degradation in the insulation of electric motors powered by frequency converters will be discussed? If the answer was yes, it remained in the previous bibliographic portfolio. If not, it was excluded. This step is justified by the fact that frequently the search for keywords in titles and abstracts allows the incorporation of works that, despite mentioning those keywords, do not deal specifically with the research topic.

Another aspect considered for selection was that the authors should address in their articles the stator insulation systems of low-voltage electric motors due to the difference that exists between these and the high-voltage motors. For low-voltage motors (nominal voltage up to $1000 \mathrm{~V}$ is considered), the coils are normally formed by electrically insulated copper circular conductors, which are inserted into the grooves manually or mechanically forming the winding of the machine. Each turn can be located anywhere in the slot, hence the name random winding. In the medium- or high-voltage motors (above $1000 \mathrm{~V}$ ), there is an option for preformed coils in which the manufacturing criteria adopted already guarantee adequate insulation and the copper wire is insulated with mica tape, resulting in an increase in final thickness of the wire insulation.

At this stage, excluded articles were subdivided into categories, which are presented, with the adopted criteria, in Table 1.

The group of articles for which the thematic relevance was not yet confirmed were not discarded because a more complete analysis had to be performed. If the article was not available in full, it had to be discarded.

To conduct a more thorough analysis, the selected articles were evaluated by reading the conclusions to determine the relevance of the knowledge presented, considering the historical evolution of the information collected and belonging to the authors who studied the researched theme the most. An article was selected if its authors presented relevant results and information about the factors that can be used in estimating the life span of the insulation of electric motors powered by frequency converters. Those articles that were considered to align remained in the list and became part of the researcher's bibliographic 
portfolio on the research topic. Also presented are a graph of the years of publication, a list of authors, and tables of the presented conferences and published journals and magazines.

Table 1. Categories of articles excluded with respective criteria adopted.

\begin{tabular}{|c|c|}
\hline Category & Exclusion Criteria \\
\hline Aircraft & $\begin{array}{l}\text { Insulation design for controlled environments and other aircraft } \\
\text { application specifics }\end{array}$ \\
\hline Converters/inverters & $\begin{array}{c}\text { Suggestions for improvements in the use and design of inverters } \\
\text { (or converters); studies on the characteristics and different types } \\
\text { of inverters (or converters) }\end{array}$ \\
\hline Experiments/tests/sensors & $\begin{array}{l}\text { Description of test methodologies to assess various motor } \\
\text { conditions and the influence of inverters (or converters), but do } \\
\text { not present information consistent with the research topic; } \\
\text { development of sensors to detect motor failure }\end{array}$ \\
\hline Filter/damper & $\begin{array}{l}\text { Development and evaluation of filters and dampers for inverter } \\
\text { (converter)/motor assembly }\end{array}$ \\
\hline Losses & $\begin{array}{l}\text { Studies of motor performance in relation to various types of } \\
\text { losses caused by use of inverters (converters) }\end{array}$ \\
\hline Types of insulation & $\begin{array}{l}\text { Evaluations of different insulation configurations and their } \\
\text { performance that do not present results in line with the } \\
\text { research theme }\end{array}$ \\
\hline Others & $\begin{array}{l}\text { Other articles that do not fit into the previous categories and are } \\
\text { not in line with the research theme, such as configurations of use } \\
\text { of power cables; studies with permanent magnets or high-voltage } \\
\text { motors or for applications in controlled environments; effect of } \\
\text { the use of inverters (converters) on bearings; aspects of bearing } \\
\text { failure; use of rectangular wires; applications with underwater } \\
\text { pumps; evaluation of surface loads and other content }\end{array}$ \\
\hline
\end{tabular}

\section{Results}

The search results in the databases of the three repositories, using the terms mentioned above, totaled 1915 records. After eliminating repeated records within each database and removing titles of proceedings and errata, the numbers decreased as follows: Scopus from 833 to 759 records, IEEE Xplorer from 791 to 750 records, and WoS from 291 to 282 records. The databases were then cross-checked, resulting in 204 articles found in the three databases, 254 articles found in Scopus and IEEE Xplorer, 34 articles found in Scopus and WoS, and 12 articles found in IEEE Xplorer and WoS. In addition, 253 articles were found only in Scopus, 30 articles only in WoS, and 278 articles only in IEEE Xplorer. Thus, the gross set totaled 1063 articles. Six other articles listed in the references of those cited above were added. There were no eliminations based on the time of publication of the articles, since evaluating the evolution of research in relation to its year of publication is also an objective of this work.

As described in Section 2.4, the thematic relevance of the 1069 articles was evaluated and the articles were subdivided into categories; these results are described in Table 2.

Thus, after reading the title and summary of the 1069 articles in the raw set, 481 articles were selected to compose the previous bibliographic portfolio. The search for complete articles was carried out in the database repositories, on the Google Scholar and ResearchGate websites, and by asking the authors to send them via e-mail. The full text of 32 articles was not found, resulting in 449 full articles to be evaluated.

A more complete analysis indicated that 219 articles did not significantly contribute to the construction of the bibliographic portfolio and 230 articles contained results indicating the main factors used in estimating the insulation life span of low-voltage electric motors. All articles in the bibliographic portfolio are presented in the bibliographic reference list. 
Table 2. Number of articles excluded from portfolio by category.

\begin{tabular}{cc}
\hline Category & Number of Records \\
\hline Aircraft & 16 \\
Converters/Inverters & 141 \\
Experiments/Tests/Sensors & 37 \\
Filter/Damper & 45 \\
Losses & 6 \\
Types of insulation & 51 \\
Others & 292 \\
Previous Bibliographic Portfolio & 481 \\
Total & 1069 \\
\hline
\end{tabular}

The number of citations in each article was also evaluated; however, as the research theme is relatively comprehensive, there was variation in both the number of articles that appeared in the searches and the number of citations in them and the scientific recognition of the articles that make up the article. The bibliographic portfolio was not a categorical decision.

In relation to the 219 files discarded because they did not contribute significantly to the construction of the bibliographic portfolio, they discussed factors that influence the life span of electric motor insulation; however, their conclusions (and in some cases, it was necessary to read the body of the article more thoroughly) did not present results on factors that can be used in the insulation life span estimation for electric motors powered by frequency converters.

For example, 36 discarded articles studied the characteristics of voltage distribution in the winding but did not discuss factors in estimating insulation life span, and in some cases, there were models to explain the voltage distribution. Another 11 articles were discarded because they explained how much the length of the power cable generates stress in the insulation but did not show results on the factors to estimate its lifetime.

In addition, 36 articles were discarded because they describe procedures for investigating insulation degradation with a focus on the development of tests or experiments for electric motors/machines that are not part of the research scope of the present work or for measuring other aspects of the motor without the presentation and discussion of results, including a state-of-the-art paper on advances in driving conditions and fault detection in electrical and power electronics machines. Another 61 articles were discarded for analyzing the aspects of partial discharges without directly relating to insulation failure, mainly the description of tests or experiments for the detection and measurement of PD statistics or measurement of inception partial discharge voltage (PDIV).

Moreover, 48 articles were discarded because they carried out studies other than those mentioned above, such as on the effect of applying tension to the film on the accumulation of spatial load and other measurements of spatial load, suggestions on techniques for choosing and designing the insulation in each application, advances in motor designs for electric cars, and evaluation of films used in the insulation system.

Finally, 27 articles, published between 1980 and 1999, were discarded due to the historical evolution of the information collected, that is, some articles were discarded because they presented conclusions that were already widely discussed and superficial.

Defining the 230 articles making up the bibliographic portfolio was not a simple task; it involved critical analysis of the articles by the researcher.

The results of the selection of articles composing the bibliographic portfolio are summarized in a PRISMA(Preferred Reporting Items for Systematic Reviews and Meta-Analyses) flow diagram (Figure 1).

Table 3 shows the journals and magazines in which 78 articles were published; three publications stand out, representing $63 \%$ of the articles. 


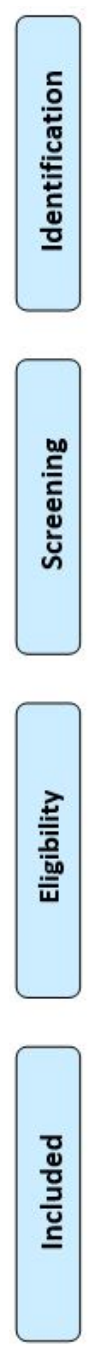

Records identified through database

searching $(n=1915)$

Scopus $(n=833)$

IEEE Xplore $(n=791)$

Web of Science $(n=291)$



Records excluded after reading the title and abstract

( $\mathrm{n}=588$ )

Subdivided into 7 categories, criteria adopted in Table 1

Studies included in

Additional records identified through other sources

$(n=6)$

Full-text articles excluded, with reasons

$$
\text { ( } n=251)
$$

Inaccessibility of full text $(n=32)$

Published more than 20 years ago $(n=27)$

Explains the voltage distribution $(n=36)$

Detection, measurement and evaluation of partial discharges $(n=61)$

Power cables $(n=11)$

Evaluation tests $(n=36)$

Others $(n=48)$

Figure 1. Selection of articles from bibliographic portfolio.

Table 3. Number of articles published in respective journals and magazines.

\begin{tabular}{cc}
\hline Publication Title & Number of Records \\
\hline IEEE Transactions on Dielectrics and Electrical Insulation & 21 \\
IEEE Electrical Insulation Magazine & 15 \\
IEEE Transactions on Industry Applications & 13 \\
IEEE Transactions on Industrial Electronics & 7 \\
Electric Power Components and Systems & 3 \\
IEEE Industry Applications Magazine & 2 \\
IEEE Transactions on Power Electronics & 2 \\
Przeglad Elektrotechniczny & 2 \\
Science China Technological Sciences & 2 \\
Archives of Electrical Engineering & 1 \\
Chinese Physics B & 1 \\
Energies & 1 \\
Engineering Computations & 1 \\
Engineering Failure Analysis & 1 \\
High Voltage Engineering & 1 \\
IEE Electric Power Applications & 1 \\
IEEE Access & 1 \\
Pransactions on Instrumentation and Measurement & 1 \\
Power Engineering Journal & 1 \\
\hline
\end{tabular}


Most of the works selected for the bibliographic portfolio were presented and published in the annals of conferences or symposiums. Table 4 shows the distribution of 152 articles according to conference/symposium title. The conference/symposium that had only one record was not added in Table 4, and the three congresses and a symposium of the first four lines of this table concentrate $45 \%$ of the articles presented.

Table 4. Number of articles presented in respective conference or symposium.

\begin{tabular}{cc}
\hline Conference/Symposium & Number of Records \\
\hline IEEE Conference on Electrical Insulation and Dielectric Phenomena & 31 \\
IEEE Electrical Insulation Conference & 13 \\
IEEE International Symposium on Electrical Insulation & 13 \\
IEEE International Conference on Properties and Applications of Dielectric Materials & 11 \\
IEEE Electrical Electronics Insulation Conference and Electrical Manufacturing \& Coil Winding & 7 \\
IEEE International Conference on Solid Dielectrics & 6 \\
IEEE International Electric Machines and Drives Conference & 5 \\
IEEE Industry Applications Society Annual Meeting & 4 \\
IEEE Annual Energy Conversion Congress and Exposition & 4 \\
International Symposium on Electrical Insulating Materials & 4 \\
International Conference on Electrical Machines & 3 \\
Electrical Insulation Conference and Electrical Manufacturing Expo & 3 \\
International Conference on Condition Monitoring and Diagnosis & 3 \\
IEEE Cement Industry Technical Conference & 3 \\
IEEE International Conference on Dielectrics & 3 \\
IEEE International Symposium on Diagnostics for Electrical Machines, & 3 \\
Power Electronics and Drives & 2 \\
IEEE International Conference on Electric Machines and Drives & 2 \\
IEEE International Symposium on Industrial Electronics & 2 \\
IEEE International Conference on Conduction and Breakdown in Solid Dielectrics & 2 \\
International Conference on Electrical Machines and Systems & 2 \\
International Conference on High Voltage Engineering and Application & \\
\hline
\end{tabular}

The articles were published between 1992 and 2020, and the distribution of the number of articles in each year is shown in the graph in Figure 2. If we divide this period in half, there are $36 \%$ of articles published in 2006 or before and $64 \%$ after. In addition, $27 \%$ of the articles were published in the last five years, confirming the growth of research on the studied topic.

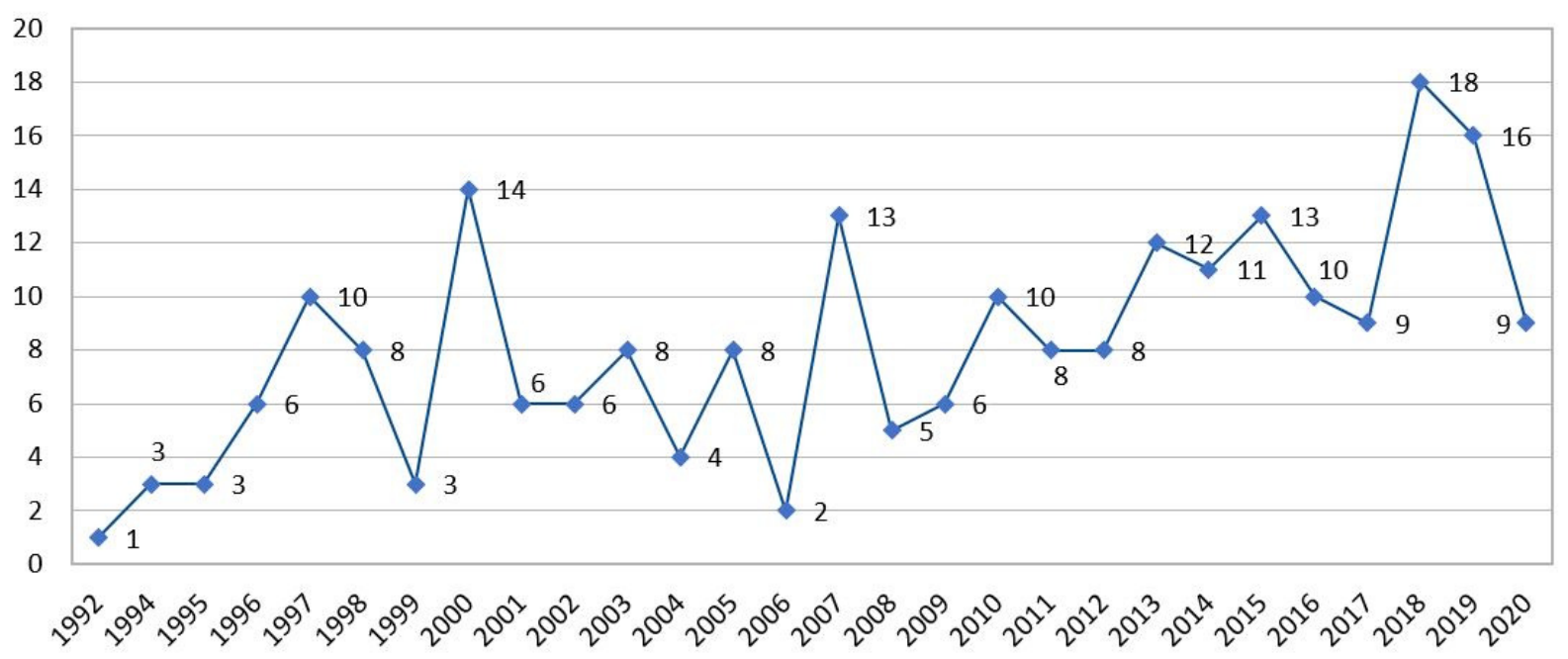

Figure 2. Number of articles in bibliographic portfolio by year of publication. 
A total of 391 authors were involved in the published works in the portfolio, in groups or individually. Table 5 shows the authors in relation to the number of papers. The other authors published less than three articles that belong to the bibliographic portfolio. Of the 230 articles, three authors stood out, participating in the publication of more than 20 articles. Hammarstrom T.J.A. stood out for publishing seven articles individually, that is, without the participation of a group of researchers. The authors presented in Table 5 determine a bank of authors who research on the topic addressed in relation to the quantity of publications, but no judgment is made regarding the quality of their publications.

Table 5. Number of articles in relation to their authors.

\begin{tabular}{ll}
\hline \multicolumn{1}{c}{ Authors } & Number of Records \\
\hline Wang, P. & 26 \\
\hline Cavallini, A. & 29 \\
\hline Montanari, G.C. & 25 \\
\hline Guastavino, F./Wu, G. & 18 \\
\hline Stone, G.C. & 14 \\
\hline Torello, E. & 12 \\
\hline Wang, J. & 11 \\
\hline Cao, K./Lebey, T. & 10 \\
\hline Luo, Y. & 9 \\
\hline Gao, B. & 8 \\
\hline $\begin{array}{l}\text { Hammarstrom, T.J.A./Hayakawa, N.A./Malec, D./Okubo, } \\
\text { H./Kim, D.H. }\end{array}$ & 7 \\
\hline $\begin{array}{l}\text { Campbell, S.R./Culbert, I./Florkowska, B./Florkowski, M./Maussion, } \\
\text { P./Nussbaumer, P./Tozzi, M./Wolbank, T.M./Zydron, P. }\end{array}$ & 6 \\
\hline $\begin{array}{l}\text { Coletti, G./Cupertino, F./Fabiani, D./Hwang, D.H./Kim, Y.J./Leuzzi, } \\
\text { R./Monopoli, V.G./Ratto, A./Vogelsberger, M.A./Xu, H./Yang, }\end{array}$ \\
\begin{tabular}{l} 
J./Zhou, K. \\
Bellomo, J.P./Cerutti, B./Cordano, D./Hameyer, K./Lusuardi, \\
$\begin{array}{l}\text { L./Martinez-Tarifa, J.M/Robles, G./Roehrich, J./Yin, W./Zanchetta, } \\
\text { P./Zhang, J. }\end{array}$ \\
\hline
\end{tabular} 5 \\
\hline
\end{tabular}

\section{Discussion}

In this section, the articles in the bibliographic portfolio are grouped to facilitate the understanding and discussion of their contributions to the knowledge about the research topic. In order for these groupings to be carried out efficiently, most of the articles were read in full, and others presented the necessary information in the summary and conclusions (previously read).

\subsection{Life Span Estimation: Review and Standards}

The normative aspects that establish the concepts of the phenomena that are present and the minimum requirements to be met in projects, tests, and performance in operation of insulating materials used in electric motors driven by frequency converters appeared in this review. In their respective articles, the authors of $[9,10]$ discuss the main characteristics of machine insulation standards and the theoretical and practical considerations of the specifications of International Electrotechnical Commission described in the original IEC 60034-18-41 and IEC 60034-18-42 standards, before the last updates [6]. In [11], some contributions were analyzed [6] and were updated relative to the tests for detecting partial discharges described in [12].

The work in [13] contributes to the characterization and testing of type I and II insulation systems, addressing issues contained in the standards $[6,14]$ and unraveling 
the potential influence of the assumptions presented in the design and qualification of insulation, and therefore in the reliability of operation of a rotating machine. The technical procedures of [6] that evaluated the quality of type I motors, partial discharge tests (offline), were summarized in [15] and used in offline and online measurements performed on a motor, highlighting the pros and cons of the specifications suggested in the standards. Another paper [16] also describes the technical specifications of the standards [6,14], mainly recognizing the potential of insulation system designs to withstand deterioration processes.

In [17], the procedures contained in the technical specification [6] for qualification testing and type for random coil motors were reported and discussed. The authors also investigated the conditions under which these prescribed procedures may fail, generating an ineffective classification, especially regarding the presence assessment of PD. In this research, the results of the measurements of partial discharges performed in twisted pairs were also presented, highlighting how the differences in the waveform of the applied voltage (applied pulse width and peak-to-peak voltage) can influence the PDIV and efficient ways to improve offline testing procedures and related equipment have been indicated.

Another paper, [18], is a review of insulation systems used in traction motors, showing that some insulation design rules were studied to adapt to the development of the converters. In addition, it indicates that more robust insulation systems are being developed to survive higher levels of electrical and thermal stresses.

An overview of the different types of high-speed electric machines together with their features and standards is presented in [19]. Also discussed are the characteristics of high-frequency PWM power supply that most influence the intensity of the partial discharge phenomenon and the rapid degradation of electrical machine insulation systems, based on the most up-to-date content in the area.

A review of the literature on the cumulative failure of the winding insulation subjected to repetitive impulse voltages was carried out in [20]. This study indicates that amplitude, frequency, polarity, and wavefront rise time of the applied impulses affect the useful life of winding insulation. It also shows that PD and the presence of spatial loads are considered the main reasons for the cumulative failure of the insulation of the motor windings, with the PD playing the dominant role. The authors believe that future challenges lie in determining the failure mechanism of the oil-impregnated paper (OIP) that has been subjected to alternating damped pulse oscillation, proposing an equivalent waveform method for double exponential pulses and alternating damped pulse oscillation, and improving the capacity of insulation winding to withstand repetitive impulse voltages.

The authors of [8] examined the mechanisms that can lead to early deterioration of the insulation of the stator winding and described the voltage resistance tests that allow motor manufacturers to develop insulation system designs that do not suffer from the effects of PWM power. A way to reduce the risk of premature failure has been defined, using a rated insulation system for higher voltages and, following the guidelines of IEC 60034-18-42, it has been suggested that tests be performed on each component to detect if any of the new failure processes are taking place, using the modified online PD test.

The authors of [21] concluded from their review that it would be advisable to establish international collaboration to systematically investigate the impact of multifactorial aging on the PDIV to assess the IEC standard and suggest improvements in the quality of insulation. They also concluded that the use of broadband devices can pose significant risks, since high switching frequencies increase the chance of overvoltages by up to three times the bus voltage.

\subsection{Life Span Estimation: Classical}

In this group of articles, three were from 2001, 2004, and 2005 [1,22,23], which were added due to the high number of citations, and 43 were published between 1992 and 2000 [3,24-65]. Thus, the articles in this group are characterized by their historical importance related to the number of citations, always evaluating whether the article highlights the factors that influence the lifetime of enameled wire insulation. 


\subsection{Life Span Estimation: Partial Discharges}

The articles in this group show that the aging of electric motor insulation arise with the occurrence of partial discharges, and it accelerates the process of degradation of the insulating medium. To construct a scenario of partial discharges, the studies reported in [2,66-77] should be considered because they seek to understand the main aspects (short rise time, high voltage magnitude, repetitive bipolar quadratic impulse voltage, etc.) that influence the appearance of PD and study their characteristics through experimental tests. The authors of [7,78-81] clarify that the useful life of magnetic wires can be determined by the total PD generation and discuss the spread of partial discharge, degradation, and life characteristics of magnetic wires for motors powered by inverters under overvoltage.

The same authors presented the influence of the parameters of the impulse waveform (rise time, frequency, and duty cycle) through PD tests in isolation models between turns in [82-89]. The results indicate that short rise times generate PD of great magnitude, degrading the insulation system faster than partial discharges initiated using waveform with longer rise times. The effect of frequency is to control the interaction between the rates of physical and chemical degradation because high frequencies generate less PD events with lower PD magnitudes and shorter delay times in a square voltage cycle. It was also confirmed that the failure times estimated by tests with sinusoidal voltages can be excessively optimistic in the evaluation of the long-term behavior of an insulation system subject to the square waveform.

Estimates of the PDIV are made in [90-95] to evaluate the propagation characteristics of PD after its onset and its mechanisms in terms of the probability of initial electron generation, the behavior of the spatial load in the air gap, and loading on the enamel surface, among others. Another paper, [96], based on an analysis of dielectric and mechanical loss of the square wave pulses, shows that PDIV increases with the increased amplitude of tension in the initial stage of aging.

In [97], the emphasis is on describing the progress in outbreak testing from a diagnostic point of view. The paper presents real measurements of outbreak environments and measures the characteristics of partial discharges during these outbreaks.

Finally, in [98], the measurement of partial discharge is evidenced as a significant instrument to indicate the quality of the winding wires and the properties of the insulating materials.

Modern methods of detecting and acquiring pulse signals help us to better understand the physical processes that lead to the onset and spread of PD in the insulation of the motor winding. Numerical proximity analyses of the electric fields were carried out with different existing winding wire models that indicated the probable causes of the degradation process of their insulating layers.

\subsection{Life Span Estimation: Insulation Tests}

This subsection presents a brief overview of the techniques and methodologies used to assess the state of the insulation of the electric motor stators, considering the articles that emerged in the search carried out in the present work. Some articles address the techniques applied without interrupting the operation of the motor called offline, which require the equipment to be decoupled for the execution of the tests, which represents the main disadvantage of this type of procedure because the tests cannot be performed often enough to ensure reliable operation of the machine until the next interruption. Despite this drawback, offline procedures are often preferable because a single test instrument can be used on multiple motors. If it is possible to monitor the condition of the insulation online, its remaining useful life could be assessed with greater precision and reliability. Catastrophic motor failures due to insulation problems can be avoided with continuous online monitoring, since insulation problems can be detected at an early stage $[4,99]$.

The article [100] can be used to guide the understanding of the types of tests for monitoring the insulation conditions of the low-voltage induction motor winding and fault detection because a comprehensive literature search on the existing methods was presented. 
The authors indicated that the online methods described are capable of identifying a turn fault, even in nonideal conditions. The evaluated offline tests, on the other hand, identify flaws and are also able to reveal the weakness in the turn insulation prior to a fault.

Considering a chronological order, the articles in the bibliographic portfolio that described online tests to assess insulation conditions, together with the principle used in the test are: [101], which assesses whether the results of the motor current signature analysis (MCSA), which identifies turns, in short, can also be used to diagnose the insulation conditions of induction motors fed by inverter and grid; [102], which has as principle the measurements of external magnetic field to detect small variations in capacitances between turns due to dielectric aging; [103], which discusses the evaluation of the transient response of the motor current in voltage pulses injected by switching the inverter; [104] and [105], in which approaches have been proposed that indicate that the leakage current measurement resulting from the high-frequency common mode component of the PWM inverter output voltage is used for the purposes of monitoring capacitance and dissipation factor; and [106], in which preinstalled current sensors detect microscopic changes that appear in their signals, and a method is proposed that quantifies these changes by machine learning.

The article [107] stands out in relation to the proposed online tests because it discusses the issue of reducing the cost of monitoring insulation with acceptable results to allow implementation and acceptance on an industrial scale. A complete, low-cost system with inexpensive shelf current sensors that monitor leakage current has been designed, built, and tested, emphasizing the short- and long-term accuracy of measurements. It is still possible to add a group of five articles [108-112] published between the years 2011 to 2015 that are being improved in relation to the test proposal, but basically identify the measurements of the current response resulting from an excitation of the voltage step of the machine by switching the inverter; this response is generally seen as a current ring signal and contains the machine's high frequency information, signal processing tools are used to extract the change information caused by the high frequency and indicate the status of isolation.

Two articles describe offline tests, the oldest of which, [113], proved that the machine's phase currents, by themselves in an inverter-powered machine (eliminating the uncertainty in the source voltage balance), provide sufficient information for a monitoring scheme of isolation. The resistance capacity of insulation materials was evaluated in [114] by applying representative high-frequency modulated signals for the supply of traditional converters, as well as waveforms with adjustable voltage pulse growth, rise time, and fall time quickly generated by new semiconductor devices.

In five other articles, the same authors also present and discuss approaches to assess the condition of isolation when the motor is not operating (offline). In [115-117], techniques were proposed that use the inverter to apply various types of test voltages to the motor and evaluate the insulation conditions based on leakage current measurements; the authors indicated that the proposed techniques are a simple and low-cost solution when the cost was compared to those of other offline inspections. In [118], the use of the offline PD test was indicated as a tool for predictive maintenance and monitoring of the condition of the quality of the insulation. The results show that the turn isolation degradation can be monitored quantitatively in an initial stage, monitoring the decrease of the PDIV. Finally, in [119], in addition to evaluating the insulation, the authors applied the proposed approach to indicate the status of other motor components: aluminum electrolytic capacitor with DC link, electrical connections, cable insulation, stator core, and the rotor cage. A summary of the failure mechanisms and existing test methods for these components was also presented.

As already described in this research, electrical stress due to the appearance of PD accelerates the insulation degradation. PD is known to occur in high-voltage machines, but it has also been reported to be detected in low-voltage motors with random coils when powered by a frequency converter [62]. In a series of three articles [120-122], the same authors examine in the first article the correlation between the offline measurements presented in [6], describing their procedures in detail. The second article presents the 
results of online PD monitoring and the third article will address the concerns of the IEC specifications, pointing out their limits. In these articles, impulsive and sinusoidal tests (offline and online) are performed with four Type I random-wound motors. Reading these articles can be the initial step to understand the scenario of PD measurements as a way to test the insulation. The work [123] can be used to learn about the progress of online PD measurement techniques.

Online PD measurement and detection is essential to avoid premature winding failure and procedures that perform these tasks are essential to determine the life span of the isolation. The authors of the present work chose not to explain the procedures contained in the next ten articles because each one has its own particularities and, if it is of interest to the readers, they can read the articles in their entirety to understand all aspects covered testing development. The works [124-129] presented techniques developed so that the manufacturers and users of electric motors guarantee the high quality of their insulation systems. These new techniques can replace conventional sensors for detecting PD (capacitive dividers or inductive sensors) that present interferences created by voltage switching that have a greater magnitude than the discharge signals and both are overlapping in the time domain. The authors of the articles [130-133] have developed offline PD measurement techniques that are normally more reliable and can be performed in a comparative way, monitoring the PD trend over the life of the motor insulation. In [134,135], new approaches to offline and online testing are proposed to resolve difficulties in PD measurements. The originality of the methods lies in the ability to extract the synchronization signal from the source regardless of its characteristics and the results of the PD detection sensitivity test are recorded using the PD detector at the motor terminal.

Finally, it is worth explaining that, despite providing important diagnoses regarding the insulation system, the detection of partial discharges is highly dependent on certain factors, such as the size of the defect, the capacitance of the winding, the inductance between the detector and the location of the PD, among others, that make it difficult to associate only the high magnitude of a PD with a more serious deterioration of the winding [8].

\subsection{Life Span Estimation: Factors}

The articles in this subsection describe and study the factors considered important for estimating the life span of electric motor insulation, or factors that can cause the insulation to age as a consequence of partial discharge activity and the formation of space charge, among other mechanisms. Table 6 describes, in chronological order, the articles that describe these factors, with the tests performed and main results presented. The articles described in Sections 4.3 and 4.5 were published between 2001 and 2015; other articles published outside this period that deal with the same subjects described in Section 4.2 are described in Section 4.7.

The same authors wrote [147-150], which present different types of insulation techniques for induction motors $(380 \mathrm{~V}, 20 \mathrm{HP})$ for inverter applications. The results of tests of PD, PDIV, dissipation factor, and rupture by high-voltage pulses are analyzed to understand the characteristics of the proposed insulation. The information in these four articles can be considered timely and reinforces an overview of options for insulation techniques and their performance.

Another set of articles [151-153] written by the same group of authors is relatively up to date. They performed resistance tests on twisted pairs, applying values above the initial partial discharge voltage, which showed that the useful life can be significantly influenced by voltage waveform characteristics (frequency and rise time). In addition, if it is confirmed that PD is the main cause of accelerated aging, the rise time should be taken into account and the sine waveform may not be the best choice for accelerated aging procedures that resemble the actual stress experienced in service by PWM. 
Table 6. Summary of contributions presented in each article in this section.

\begin{tabular}{cll}
\hline Article & \multicolumn{1}{c}{ Tests } & \multicolumn{1}{c}{ Main Results } \\
\hline [136] & $\begin{array}{l}\text { Abrasion by mechanical scraping, initial corona tension, } \\
\text { dielectric strength, and pulse power resistance, with six types } \\
\text { of wires from three manufacturers. }\end{array}$ & $\begin{array}{l}\text { Filled polyimide material lasted longer at the set frequency and } \\
\text { voltage level. Filled polyimide material is in a higher temperature } \\
\text { class that allows overload conditions. }\end{array}$ \\
\hline [137] & $\begin{array}{l}\text { Aging with the application of different electrical voltages by } \\
\text { means of dielectric spectroscopy, which uses sinusoidal } \\
\text { currents and voltage measurements to obtain impedance } \\
\text { characterization at the selected frequencies. }\end{array}$ & $\begin{array}{l}\text { The tested frequency bands allowed us to indicate the insulation } \\
\text { conditions, observing a trend of growth in conductance as a function } \\
\text { of time for each selected frequency. The conductivity effect may be } \\
\text { hidden in these high frequency bands and they occur due to the high } \\
\text { frequency behavior of complex susceptibility that generates } \\
\text { electrical stress. }\end{array}$ \\
\hline
\end{tabular}

Aging of model bar samples with unipolar sinusoidal voltage pulses $(60 \mathrm{~Hz})$ and fast repetitive and high-frequency waveforms in the presence of PD activity. To establish the residual resistance of magnetic wire samples with polyimide and nanofilled coating, breakdown voltage is determined before and after aging.

PD activity is mainly triggered due to high voltages between two adjacent wires, which can be affected by accumulated spatial load in the insulation and between two interfaces. Magnetic wires with nanofilled discharge-resistance materials do not always have life-cycle improvements, especially in pulse applications.

Decomposition points are analyzed using energy spectrum analysis and electron microscopy photography. The breaking mechanism of polyimide corona resistant film and traditional polyimide film is explained by microfissure theory.

Although inorganic fillers do not increase resistance to degradation of polyimide film, inorganic fillers in the film greatly increase resistance to insulation degradation caused by partial discharge, dielectric heating, and space charge.

Differences between AC (alternating current) aging and square

[140] wave pulse aging are studied based on $\tan \delta$ and PD pattern Thermally stimulated current (TSC) proves that square wave pulses bring more defects than AC to insulation materials. With that, damage action of PD is intensified with increased voltage, frequency, change curves. and temperature, as well as increased space charges.

The performance of voltage grading coatings is calculated under the combined effect of high fundamental frequency and voltage distortion; resistive heat is also calculated for different voltage distortion conditions.

Changes in the aging structure of polyimide film under pulse voltage above the PDIV is investigated by scanning electron microscopy (SEM), TSC, and lifetime test.

Application of semisquare impulse voltage on a surface of two types of insulation systems: ethylene propylene rubber (EPR)

[143] and thermosetting insulation samples, representing cable and machine insulation systems, development of ionization processes, and impact of space charge.

Evaluation of PD patterns with phase resolution recorded using the phase resolved partial discharge (PRPD) acquisition method. Break times for wires of different diameters are evaluated for trapezoidal voltages with a frequency of $10 \mathrm{kHz}$.

Aging of spiral insulation samples under bipolar voltage with continuous quadratic impulse. Number and average number of PD under impulse voltage are calculated. Microcosmic morphology of the insulation of the turn surface is analyzed with SEM.

An aging system under continuous square impulse bipolar

[146] voltage (BCSIV) is designed to explore the damage mechanism of PI film caused by partial discharge, and electrical aging tests of PI film samples are above the PDIV.
Generation of resistive heat can be increased by pulse rise time, and increase can be considerably greater with increased fundamental frequency. Resistive heat generation is more affected by switching frequency.

Degradation of polyimide structure spreads from surface to interior with continuous aging, creating three layers in sections. Two main well-resolved peaks are in the TSC spectrum in the range of 20 and $200{ }^{\circ} \mathrm{C}$ and degradation accelerates with increasing frequency.

Mechanism, intensity, and dynamics of polymer insulation degradation in PWM type voltage are the consequence of pulse voltage waveform, mainly with short rise time, overvoltages, and the high frequency of pulse repetition. Local electric field causes structural changes in polymer insulation during PD exposure.

Voltage, frequency, and pulse increase/decrease time affect PD in the impulse voltage. Voltage rise time has a particular impact on initiation conditions and partial discharge initiation voltage. Diameter of magnetic wires and their location in the winding determine electric field distribution and influence insulation life.

Results reveal that the relationship between PD parameters (number and average amount of PD) and aging time is complicated. Damage to polyimide nanocomposite film structure is concentrated on degradation of the polymeric matrix in the presence of PD.

The change in the microscopic structure of the PI polymer can alter the organizing capacity of the polarizable units when the samples are under the electric field, causing the dielectric constant to increase and the $\tan \delta$ dielectric loss to decrease. The physical and chemical effects of PD break the chemical bonds in the polymer chains of PI.

A series of articles published between 2001 and 2015 [154-166] make up a broad study by a group of authors researching the insulation performance of electric motors that are part of modern drives (equipped with inverters/converters). In particular, the effects of the degradation of partial discharges (PD) were studied experimentally to evaluate the effects of different voltage waveforms (peak-to-peak voltage levels greater than the initial voltage of PD and fundamental frequency of $300 \mathrm{~Hz}$ ), near-square voltages, and voltage rise time. All tests were carried out in the presence of partial discharge activity and with the specimens inside a greenhouse in order to apply the synergistic effect of thermal stress 
to enamel degradation. Rupture of the insulating enamel was defined as the endpoint criterion. Some types of enamel were considered (conventional reference nonresistant to corona and nanofilled enamels). The main results confirmed the dependence on the characteristics of nanofilled enamel to avoid accelerated degradation.

A final set of articles [167-169] perfectly represent the work group in this subsection because they describe the factors involved in degrading the insulation, the role of partial discharges, and the basic causes and effects of the high-growth environment of the pulse tension, among other aspects. In addition, they briefly review the NEMA (National Electrical Manufacturers Association) and IEC standards that attempted to partially solve the problems. Tests of motor insulation systems to verify conformity with the submitted requirements are also explained.

\subsection{Life Span Estimation: Models}

The 19 articles in this group evaluate the aging process and propose models that allow estimation of the lifetime of the materials that make up electric motor insulation. Accelerated aging tests were carried out and the experimental data were used for both elaborating the models and comparing their results. Table 7 presents the statistical (or mathematical) tools, the factors evaluated, and the materials used in the tests for the 16 articles in this section.

The authors of [186] present the same models and results as [179] in that paper and were not excluded because it came up in the search with different titles and abstracts.

One article, [187], stands out in this group because it covers the problem of lifetime modeling for electrical machine insulation systems with three tested enameled insulation materials (Kapton film, polyesterimide film, and twisted pairs). They show that several regression methods can provide satisfactory multiconstraint models. The DoE and response surface are the most precise and with restricted experimental cost, whereas multilinear regression is more flexible.

Finally, another article, [188], in which a model that calculates the probability of failure of the motor winding due to overvoltage related to premature aging, relative to the operating time within a considered configuration, is presented, was added to this group. The setting involves the frequency of the test voltage, the frequency of the voltage histogram, and the starting voltage of the PD.

\subsection{Life Span Estimation: Current}

This subsection is the most important one in the section because it presents the research carried out in the last five years (from 2016 onward) that discusses aspects related to the causes of degradation, highlighting the main factors that must be considered to estimate the life span of electric motor insulation. There are 50 articles, which are described according to their similarity in relation to their contribution to the research topic and their authorship by groups of researchers.

The problems associated with measuring and detecting partial discharge (PD) are addressed in [189]. This is a fundamental tool for the design and diagnosis of insulation systems because during their lifetime, they should operate without degradation, but this does not necessarily occur in practice. In this sense, it is also important to calculate the PDIV, since the estimated motor insulation life also depends on this value. 
Table 7. Tools, stress factors, and types of samples in each article.

\begin{tabular}{|c|c|c|c|}
\hline Article & Modeling Methods & Stress Factor & Samples \\
\hline [170] & $\begin{array}{l}\text { Inverse power, design of } \\
\text { experiment (DoE) }\end{array}$ & $\begin{array}{c}\text { Voltage } \\
\text { Temperature } \\
\text { Voltage, temperature, and frequency }\end{array}$ & Magnet wire insulation \\
\hline [171] & Weibull distribution & Voltage magnitudes, temperature, and frequency & Magnet wire insulation \\
\hline [172] & Inverse power & Voltage & $\begin{array}{l}\text { Insulation tape and } \\
\text { impregnant material }\end{array}$ \\
\hline [173] & $\begin{array}{l}\text { Binary Weibull } \\
\text { distribution function }\end{array}$ & Voltage and frequency & Polyimide film \\
\hline [174] & Arrhenius equation & Temperature & Enameled wire (twisted pair) \\
\hline [175] & Inverse power, DoE & $\begin{array}{c}\text { Voltage } \\
\text { Temperature } \\
\text { Frequency } \\
\text { Voltage, temperature, and frequency }\end{array}$ & Coated steel plate \\
\hline [176] & Inverse power, DoE & $\begin{array}{c}\text { Voltage } \\
\text { Temperature } \\
\text { Frequency } \\
\text { Voltage and temperature } \\
\text { Voltage and frequency } \\
\text { Temperature and frequency } \\
\text { Voltage, temperature, and frequency }\end{array}$ & Coated steel plate \\
\hline [177] & Inverse power & Frequency & Paper insulation \\
\hline [178] & Weibull statistical method & $\begin{array}{l}\text { Voltage, temperature } \\
\text { Voltage, frequency } \\
\text { Temperature, frequency }\end{array}$ & Polyimide film \\
\hline [179] & Weibull statistical method & $\begin{array}{c}\text { Voltage } \\
\text { Temperature } \\
\text { Frequency, temperature, and voltage } \\
\text { Temperature and frequency } \\
\text { Temperature and frequency }\end{array}$ & Polyimide film \\
\hline [180] & Fuzzy logic & $\begin{array}{l}\text { Voltage stress factor, spike frequency factor, and } \\
\text { waveform slope stress } \\
\text { factor }\end{array}$ & Polyimide film \\
\hline [181] & Fuzzy logic, DoE & $\begin{array}{l}\text { Voltage stress factor, spike frequency factor, and } \\
\text { waveform slope stress factor }\end{array}$ & Polyimide film \\
\hline [182] & Weibull distribution, DoE & Voltage and frequency & $\begin{array}{l}\text { Enameled wire } \\
\text { (twisted pair) }\end{array}$ \\
\hline [183] & Weibull distribution, DoE & $\begin{array}{c}\text { Voltage and frequency } \\
\text { (Three magnet wires of different lifespans) }\end{array}$ & $\begin{array}{l}\text { Enameled wire } \\
\text { (twisted pair) }\end{array}$ \\
\hline [184] & Weibull distribution, DoE & $\begin{array}{l}\text { Voltage, temperature and frequency } \\
\text { (Three magnet wires of different lifespans) }\end{array}$ & $\begin{array}{l}\text { Enameled wire } \\
\text { (twisted pair) }\end{array}$ \\
\hline [185] & Inverse power & Voltage and frequency & Enameled wire \\
\hline
\end{tabular}

The correlation between PDIV and wire thickness, considering thermal degradation, was studied in [190]. The authors of [191] reported that a model for PDIV in stators of induction machines seems viable if it is accepted that PDIV is underestimated by the selection of a conservative value for the constant $K$ in an equation described in the work that represents a function of the product $p \times d$ (gas pressure times gap length, assuming a uniform field). Some limitations in this approach have been found when dealing with extremely thin wires, which may not be of practical interest for power drives. The inception repetitive partial discharge voltage (RPDIV) was measured at [192] and it was found that 
its values may depend on the characteristics of the source used soon; it is advisable to use repetitive square waves to decrease measurement errors while maintaining the potential of tensioning the winding insulation. In addition, the definition of RPDIV seems to need more in-depth research to understand how reported fluctuations (during individual mensuration) and conditioning (in repeated mensuration) reported in this paper should be dealt with to obtain data possible to repeat and precise results. The authors of $[193,194]$ describe a methodology that can be applied to assess whether using materials resistant to PD is an appropriate approach to design machines that operate with fast switching inverters. For the studied samples, it was shown that the useful life advantage of PD-resistant wire only exists below a frequency limit. Above that frequency, there is a drastic drop in life span, making the supplied enameled wire unsuitable for operation at high frequencies and voltages. In [195], a model that uses the volume-time theory to calculate the PDIV of twisted pairs of enameled wires is presented. The simulation results are compared to PDIV measurements for bipolar voltage pulses with short rise times.

The next seven articles were written by the same author. One article [196] gathers the conclusions of [197] (written with two more authors) and [198], which studied the influence of the choice of PWM level (inverters of two, three, four, or five levels) and rise time on PD characteristics. The results presented in the studies suggest that the basis for the relationship between PD exposure remains valid for various insulation materials by increasing the number of PWM levels from two to five. They also show that total PD exposure decreases significantly when a three-level inverter is used for both materials (pure polyamide-imide or $\mathrm{Cr}_{2} \mathrm{O}_{3}$ material added). Maximum PD, however, remain at approximately the same magnitude until the PWM level reaches four or more, when increasing the number of steps results in little influence on the number of detected PD. The use of even higher inverter levels influences the characteristics of PD in a similar way. Those three articles are complemented by [199,200]. It is reported in [199] that a shorter rise time of the inverters increases the PD exposure within the winding insulation, as well as much smaller voltage steps, indicating the importance of carrying out tests using suitable waveforms. The other study [200] indicates that a high-level inverter is a multitask tool for testing and evaluating materials, providing more information than conventional PD research. The implications of the PDIV level, the rise time, and the PWM level, by applying a multilevel waveform, can be used to evaluate the electrical features and facilitate the research for new insulation materials. In the methodology presented in the article, these parameters are monitored online, enabling degradation studies and decomposition time measurements.

In another paper by the same author [201], a test method is presented to detect the presence of PDs using waveforms similar (or close) to those used in applications to evaluate the influence of rise times, reflections, and insulation conductivity in single twisted pair test samples or complete windings. The waveform is generated by the application of a new three-level inverter circuit. The results of the initial measurements of twisted pair tests were presented to look like a random winding motor. The most recent work by this author, [202], contains examples of how the voltage supply circuits can be designed so that the PD exposure inside the motor windings is reduced considerably by adjusting the rise time of the wave supplied on the voltage flanks where the electric stress has the greatest magnitude. To clarify this approach, changes were made to the inverter levels to assess the characteristics of the partial discharge by applying adjustable rise times. Other works by the same author can be found in the bibliographic references of the articles cited; however, they did not appear in the databases search.

Thorough research by the authors Wang et al. [203-211] resulted in nine articles that analyze statistics of PDs and resistance of enameled wires aiming to evaluate the performance of the insulation systems of type I low-voltage motors. Briefly, the main results were as follows: 
i. Under square repetitive waveform, the amplitude of PD is seven times greater than under sinusoidal voltage; therefore, it is recommended to generate the voltage stress as the converter output [203] (p. 4).

ii. The resistance obtained in sinusoidal voltage is three times greater than in repetitive square wave voltage with a rise time of 200 ns. Therefore, sinusoidal voltage with the same peak value and frequency as repetitive impulsive voltage cannot be used to assess the performance of the corona resistance of insulation systems for inverter-powered motors [203] (p. 4).

iii. The effect of temperature on PD magnitude and delay time is more significant at low frequency; that is, a higher temperature will give rise to PD events with longer magnitude and delay time [204] (p. 205).

iv. When performing PDIV and resistance tests on insulation systems of rotating machines powered by power electronics in accordance with IEC standards, not only the rise time but also the drop time of the impulsive voltages must be carefully considered [205] (p. 696).

v. Small square voltage duty cycles (with duty cycle equal to 50\%) can induce asymmetric PD patterns and extend the life of the insulation due to a substantial reduction in the magnitude of PD on the downward flank of the applied voltage [211] (p. 145).

vi. The resistance of the polyimide decreases with increased switching frequency and tends to increase with the fundamental frequency in the SPWM with the same switching frequency [211] (p. 145).

A group of authors [212] tested three types of enamel (conventional, microfilled, and nanofilled) considering two voltage waveforms (sinusoidal and similar to PWM) and applying different voltage amplitudes to the samples. The aging tests demonstrated better long-term behavior of the corona resistant B enamel considering the sinusoidal and PWMlike waveforms. As expected, the PWM waveform degraded the insulation faster than the sine waveform. In [213], three types of stator insulation systems (without impregnation, polyester resin bath impregnation, and epoxy resin encapsulation without vacuum) were tested for different amplitudes and waveforms in an attempt to correlate RPDIV and PDIV with temperature variation. At temperatures close to operating conditions, PDIV and RPDIV were close for the three types of insulation systems. Impregnation and encapsulation of the vacuum-free bath had good mechanical winding resistance; however, in operating temperature conditions they were ineffective at improving PDIV and RPDIV values. Screening of various insulation systems consisting of conventional organic enamel as a primary insulation system and impregnation resins as secondary insulation system was presented in [214]. There was a selection, among those tested, of the most promising materials in relation to the lifetime, considering voltage amplitude slightly greater than PDIV.

The previously cited articles discussed various aspects of PD generation and impact that should be evaluated when studying the life of the insulation of magnetic wires. An effective analysis of these aspects is also sought in [215-221]. Here, we highlight [222,223], which are current and make a complete study with experimental results and theoretical contributions. Both should be used as references when it comes to understanding the factors (short rise times and the presence of overvoltages that occur repeatedly) that significantly overload the insulation of power cables and motors, remembering that these factors influence the onset and dynamics of PD and the process of accumulation of space charge.

The articles described below confirm the experimental investigations of the effects caused by the supply of the PWM inverter in the insulation system of an electric motor. Among them, the best solution to contrast the harmful effects of high frequencies is given by adequate insulation of the stator winding, which allows it to withstand higher peak voltage before experiencing partial discharge. Furthermore, it is likely that the combination of a robust stator insulation system with the appropriate choice of cable between the inverter and the motor will result in a lower reflection factor and, consequently, a lower voltage value peak at the motor terminals. 
Several articles [224-226] present similar conclusions when testing the switching frequency as the main stress factor, because it is noted that when the frequency is increased from 10 to $30 \mathrm{kHz}$, the breaking properties of the waveforms impose a deterioration rate of the insulation system and the PWM peak waveform is faster than the PWM waveform. This indicates that the life of the motor insulation will be reduced if the insulation is more stressed. It is also reported that the breakdown voltage reduction is $17 \%$, but it is $25 \%$ only in the PWM waveform. Another observation was that the increase in rupture stress and resistance capacity is almost linear for the secondary layer with nanocomposites than the layer without for the power frequency. The same does not happen with high-frequency PWM stress, as the linearity absent in the general profile observed in the power frequency is also maintained here.

The authors of $[227,228]$ present a new approach that adopts three indices to show the progression of electrical aging through the evaluation of the effects in the entire stator winding insulation system, measuring macroscopic quantities such as impedance and high frequency currents. Interpretation of the cumulative effect of random changes that occurred in different locations and at different rates within the isolation system was performed. Regarding the calculations of the indices, although the integral deviation performs better than the absolute deviation in describing the motors aging path, the differential deviation can give a useful indication of the intensity of the variations between two consecutive aging stages. The same authors in [229] describe a high-frequency model capable of simulating the effects, which occur in different time domains, resulting from electrical aging in the performance of the motor under PWM power. The results of the simulation are shown to prove the feasibility of the proposed control approach.

Another article, [230], contains the results of investigating the insulation of magnetic wires with different diameters in a standardized sample model to evaluate their resistance to exposure in pulse voltages. The diagnostic parameters of stator winding insulation with several years of service are measured in [231], including insulation resistance, dissipation factor, inception partial discharge voltage (PDIV), and residual rupture voltage. A simple technique was proposed in [232] to identify whether the modification in insulation resistance between the turns affects the capacitive component of the stator line current. The measurement of the insulation resistance was performed, generating a different voltage waveform and studying the faults between turns. The work [233] presents a methodology that allows, in combination with finite element simulations, to identify the critical points of electric fields that can deteriorate the insulation of the entire winding system. It has been shown that it is not enough to design and improve the insulation system with simulations of electrical loads alone.

Finally, articles by the same authors [234-236] were not excluded from the bibliographic portfolio because similar simulations and tests were performed with a demagnetized rotor installed to study how the protrusion overhang affects propagation and tension stress. The winding stress propagation measured for all scenarios generally agreed with the results of the elaborated high-fidelity finite element (FE) models. The measured and simulated results show good consistency. The effects of wire positions on voltage stress and current distribution were also investigated in [234] through simulations and tests, and voltage stress was mapped in each part along the winding to various points of operation of the machine.

\section{Conclusions}

In this paper, we present a systematic review of the literature to provide researchers and design engineers with an overview of the causes of degradation of the insulation of electric motors powered by frequency converters, which may point to possible directions for future research activities. The countless results that appear in the databases need to be filtered in this way; the constructed bibliographic portfolio directs researchers, in an objective way, to works that can contribute to the understanding of the researched theme. 
It was essential to assess each article individually, because in several cases, the title or abstract presented a broad idea and specific results were discussed in the text.

Most of the articles in the bibliographic portfolio were presented and published in conference proceedings or symposiums, with the IEEE Conference on Electrical Insulation and Dielectric Phenomena accounting for $20 \%$ of the 152 articles. Another 78 articles were published in journals or magazines, most of them in IEEE Transactions on Dielectrics and Electrical Insulation, IEEE Electrical Insulation Magazine, and IEEE Transactions on Industry Applications, accounting for $63 \%$ of the articles.

The authors with the most articles in the bibliographic portfolio are Wang, P., Cavallini, A. and Montanari, G.C., all of whom published more than 20 articles; Guastavino F. and $\mathrm{Wu}, \mathrm{G}$. with 18 articles each; and G.C. Stone with 14 articles. These authors usually publish with groups of researchers.

No choice was made regarding the time of publication, since evaluating the historical evolution of the information was also one of the objectives. However, the articles were analyzed with regard to their year of publication. Figure 2 shows that there was an increase in the number of published articles and that $27 \%$ of the articles making up the bibliographic portfolio were published in the last five years.

It is believed that any study on the degradation and lifetime of insulation should consider the normative aspects that establish the concepts of the phenomena that are present, the minimum requirements to be met in projects, tests, and performance in the operation of insulating materials. Thus, Section 4.1 brings together the works that deal with these aspects. The content of review articles that addressed the research topic was also summarized in this subsection.

As observed in the conclusions of the evaluated works, the degradation of insulation occurs due to the effects of several factors; the main stress factor considered in the studies was exposure to high-voltage spikes caused by the rapid growth of pulses generated by the inverter (rise time), as well as the high frequency with which these peaks are produced. The works described in Section 4.2 demonstrate that this has been discussed since the first publications.

Electric stress and differences in the electrical permittivity of the air facilitate the formation of high potential gradients, which can exceed the PDIV and lead to partial discharges. Various aspects related to the appearance and characteristics of partial discharges were covered in the works described in Section 4.3 and must be studied to understand the aspects of estimating the lifetime of insulation.

Partial discharges in an insulating system do not mean immediate failure of the insulation, but long exposure to partial discharges causes deterioration in the insulating materials, and the time for breakdown of the dielectric of an insulation system depends on the intensity of the partial discharges, the threshold voltage to start the discharges, the thickness of the insulating materials involved, and the resistance to erosion of each particular material. The threshold voltages, and consequently the service life, will also be greater depending on the quality of the impregnation of the winding coils. This quality depends on the impregnating material and the percentage of retained solids filling the spaces between the conducting wires. All of these are important for estimating the useful life of insulation and were confirmed in the articles in Section 4.5.

The evaluation of the insulation conditions of low-voltage electric motors with random windings is necessary to minimize impacts with loss of production or corrective maintenance. For this, several studies and techniques have been developed and those that emerged in the search carried out in the present work are presented in Section 4.4. However, each procedure adopted was not explained in detail due to its particularities and it is suggested to read the articles in their entirety to understand all aspects covered in the development of the tests. It is noteworthy the fact that a single test is not able to cover all types of problems to which the insulation motor is susceptible; therefore, it is necessary to carry out more than one procedure to expand the diagnostic capacity. 
Estimating the effective lifetime of insulation as a function of a multiplicity of factors is a highly complex task, where the effects of variations in the construction process, the physical-chemical reactions of the insulating materials, temperature, and electric stress interact. In the articles in Section 4.6, various models are presented that list the multiple stressors. They allowed to evaluate the expected trends for each case, in addition to experimental tests that provided useful data for predicting the life span of electric motor insulation.

Table 8 was constructed to summarize the main contributions of the articles in the bibliographic portfolio, except for the articles in Sections 4.1 and 4.2 and those described in Table 6.

Table 8. Main contributions of each article.

\begin{tabular}{|c|c|c|c|}
\hline $\begin{array}{c}\text { Object of } \\
\text { Study }\end{array}$ & Mo & t Relevant Contribution & Article \\
\hline \multirow{16}{*}{$\begin{array}{c}\text { Partial } \\
\text { Discharge }\end{array}$} & \multirow{6}{*}{$\begin{array}{l}\text { Evaluated } \\
\text { factors }\end{array}$} & Peak voltage & {$[66,73,79,84,197,198,218]$} \\
\hline & & Rise time & {$[66,68,74,75,88,89,194,196,220,221]$} \\
\hline & & Switching frequency & {$[69,74,75,193,194,219]$} \\
\hline & & Waveform & {$[69,70,72,76,82,83,85-87,91,199,203,205-211,216,220,221]$} \\
\hline & & Converter level & {$[196-198,200,221]$} \\
\hline & & Temperature & {$[204,215,218]$} \\
\hline & \multicolumn{2}{|c|}{ Confirms insulation degradation } & {$[2,67,77,78,90,222]$} \\
\hline & \multicolumn{2}{|c|}{ Characteristics versus degradation } & {$[71-73,76,78-81,90,92]$} \\
\hline & \multicolumn{2}{|r|}{ Detection } & {$[189,201,217,222,223]$} \\
\hline & \multicolumn{2}{|r|}{ Improved effects } & [202] \\
\hline & \multirow{3}{*}{ PDIV } & Measurement & {$[86,87,90-93,95,190,192,195,223]$} \\
\hline & & Improvements & [191] \\
\hline & & Related factors & {$[80,94,96,192]$} \\
\hline & \multirow{3}{*}{ Wire resistance } & $\mathrm{PD}$ & {$[212]$} \\
\hline & & PDIV & {$[213,214]$} \\
\hline & & RPDIV & [213] \\
\hline \multirow{10}{*}{$\begin{array}{l}\text { Insulation } \\
\text { life span }\end{array}$} & \multicolumn{2}{|r|}{ Models } & [170-188] \\
\hline & \multicolumn{2}{|r|}{ Insulation techniques } & {$[147-150,231,233]$} \\
\hline & \multirow{2}{*}{ Presence of PD } & Waveform and rise time & {$[151-153,232]$} \\
\hline & & Wire resistance (experimental tests) & [154-166] \\
\hline & \multirow{2}{*}{$\begin{array}{l}\text { Degradation } \\
\text { factors }\end{array}$} & $\begin{array}{l}\text { Regarding the } \\
\text { technical specifications }\end{array}$ & {$[167-169,230]$} \\
\hline & & Switching frequency & [224-226] \\
\hline & \multicolumn{2}{|c|}{ Indices for electrical aging } & {$[227,228]$} \\
\hline & \multicolumn{2}{|c|}{ Simulate the effects of electrical ageing } & [229] \\
\hline & \multicolumn{2}{|r|}{ Insulation monitoring } & [100-135] \\
\hline & \multicolumn{2}{|r|}{ Voltage distribution } & [234-236] \\
\hline
\end{tabular}

Finally, research carried out in the last five years (from 2016 onward) is presented in the articles in Section 4.7 and all aspects related to the causes of degradation are comprehensively discussed. It can be seen that even in these current works, the authors highlight that the main factors that must be considered to estimate the life span of electric motor insulation are the same ones that were researched in the last 20 years. However, there was an evolution in the publication and updating of technical specifications (standards), mainly identifying the capacity of several insulation systems to resist additional deterioration processes and helping to improve electric motor design. Yet from the experimental results presented in these works, it was evident that the characteristics and thickness of the 
insulating materials and the strength of each particular material can improve the resistance to erosion. Coating with nanocomposite filling (as a secondary layer or not) was evaluated and tested in several articles as a way to avoid degradation of the insulation of electric motors driven by frequency inverters.

Scientific production points to signs of continued growth in the coming years, and researchers who already have a wealth of information at their disposal may find themselves unable to take advantage of all of the available information, making it necessary to selectively choose the content to be considered in research. The difficulty in establishing selection criteria and following a rigorous process in the search for relevant information highlights the importance of the present work, which presents an objective direction for the selection of bibliographic references for scientific research.

As future work, the authors are developing a model that uses a system based on fuzzy rules to quantify the lifetime of the enameled wire, and the knowledge acquired with the present research was useful in delimiting the variables and model validation.

Author Contributions: All authors have read and agreed to the published version of the manuscript.

Funding: This research received no external funding.

Institutional Review Board Statement: Not applicable.

Informed Consent Statement: Not applicable.

Data Availability Statement: The article information collected in this review is data available in publicly accessible repositories: IEEE Xplore (https:/ / ieeexplore.ieee.org/Xplore/home.jsp); Scopus (https://www.scopus.com); Web of Science (https:/ / mjl.clarivate.com/home) and were accessed on 20 October 2020.

Acknowledgments: The authors are grateful for the financial support received from the Federal Institute of Education, Science and Technology of Santa Catarina (IFC), Brazil.

Conflicts of Interest: The authors declare no conflict of interest.

\begin{tabular}{|c|c|}
\hline \multicolumn{2}{|c|}{ Abbreviations } \\
\hline \multicolumn{2}{|c|}{ The following abbreviations are used in this manuscript: } \\
\hline $\mathrm{AC}$ & Alternating current \\
\hline DoE & Design of experiment \\
\hline IEC & International Electrotechnical Commission \\
\hline IEEE & Institute of Electrical and Electronics Engineers \\
\hline IEEJ & Institute of Electrical Engineers in Japan \\
\hline NEMA & National Electrical Manufacturers Association \\
\hline PDIV & Inception partial discharge voltage \\
\hline PWM & Pulse width modulation \\
\hline RPDIV & Inception repetitive partial discharge voltage \\
\hline SEM & Scanning electron microscopy \\
\hline TSC & Thermally stimulated current \\
\hline
\end{tabular}

\section{References}

1. Wheeler, J.C.G. Effects of Converter Pulses on the Electrical Insulation in Low and Medium Voltage Motors. IEEE Ind. Appl. Mag. 2005, 5, 41-47. [CrossRef]

2. Fenger, M.; Campbell, S.R.; Pedersen, J. Motor winding problems caused by inverter drivers. IEEE Ind. Appl. Mag. 2003, 9, 22-31. [CrossRef]

3. Kaufhold, M.; Aninger, H.; Berth, M.; Speck, J.; Eberhardt, M. Electrical stress and failure mechanism of the winding insulation in PWM-inverter-fed low-voltage induction motors. IEEE Trans. Ind. Electron. 2000, 47, 396-402. [CrossRef]

4. Stone, G.C.; Boulter, E.A.; Culbert, I.; Dhirani, H. Electrical Insulation for Rotating Machines: Design, Evaluation, Aging, Testing, and Repair; IEEE Press: Piscataway, NJ, USA, 2004; ISBN 9780471682899.

5. Association for Instrumentation, Control, Automation (GAMBICA); Rotating Electrical Machines Association (REMA). Motor Insulation Voltage Stresses under PWM Inverter Operation, 4rd ed.; Technical Report; GAMBICA-REMA: London, UK, 2016. 
6. IEC 60034. Rotating Electrical Machines_Part 18-41: Partial Discharge Free Electrical Insulation Systems (Type I) Used in Rotating Electrical Machines Fed from Voltage Converters-Qualification and Quality Control Tests; International Electrotechnical Commission: Geneva, Switzerland, 2014.

7. Hayakawa, N.; Inano, H.; Nakamura, Y.; Okubo, H. Time variation of partial discharge activity leading to breakdown of magnet wire under repetitive surge voltage application. IEEE Trans. Dielectr. Electr. Insul. 2008, 15, 1701-1706. [CrossRef]

8. Stone, G.C.; Culbert, I. Review of stator insulation problems in medium voltage motors fed from voltage source PWM drives. In Proceedings of the 2014 International Symposium on Electrical Insulating Materials, Niigata, Japan, 1-5 June $2014 ;$ pp. 50-53.

9. Stone, G.C.; Stranges, M.K.W. New IEC standards for qualifying stator insulation systems for PWM converter drives. In Proceedings of the 2007 Electrical Insulation Conference and Electrical Manufacturing Expo, Nashville, TN, USA, 22-24 October 2007; pp. 94-97.

10. Stranges, M.K.W.; Stone, G.C.; Bogh, D.L. Progress on IEC 60034-18-42 for Qualification of Stator Insulation for Medium-Voltage Inverter Duty Applications. In Proceedings of the 2007 IEEE Petroleum and Chemical Industry Technical Conference, Calgary, AB, Canada, 17-19 September 2007; pp. 1-7.

11. Kimura, K. The role of IEC 60034-27-5 for IEC 60034-18-41: Offline PD test methods with repetitive impulse voltage. In Proceedings of the 2017 International Symposium on Electrical Insulating Materials (ISEIM), Toyohashi, Japan, 11-15 September 2017; Volume 1, pp. 155-158.

12. IEC 60034. Rotating Electrical Machines-Part 27-5: Off-Line Partial Discharge Tests on Winding Insulation of Rotating Electric Machine During Repetitive Impulse Voltage Excitation; International Electrotechnical Commission: Geneva, Switzerland, 2016.

13. Montanari, G.C. Characterizing insulation systems of rotating machines controlled by power electronics: The role of partial discharges. In Proceedings of the 2015 IEEE 11th International Conference on the Properties and Applications of Dielectric Materials (ICPADM), Sydney, NSW, Australia, 19-22 July 2015; pp. 15-21.

14. IEC 60034. Rotating Electrical Machines-Part 18-42: Partial Discharge Resistant Electrical Insulation Systems (Type II) Used in Rotating Electrical Machines Fed from Voltage Converters; International Electrotechnical Commission: Geneva, Switzerland, 2017.

15. Cavallini, A.; Montanari, G.C.; Tozzi, M. Electrical aging of inverter-fed wire-wound induction motors: from quality control to end of life. In Proceedings of the 2010 IEEE International Symposium on Electrical Insulation, San Diego, CA, USA, 6-9 June 2010; pp. 1-4.

16. Culbert, I. Experience with partial discharge testing during voltage surges as required by IEC 60034-18-41 and 60034-18-42. In Proceedings of the Conference Record of 2009 Annual Pulp and Paper Industry Technical Conference, Birmingham, AL, USA, 21-26 June 2009; pp. 156-160.

17. Cavallini, A.; Lindell, E.; Montanari, G.C.; Tozzi, M. Off-line PD testing of converter-fed wire-wound motors: when IEC TS 60034-18-41 may fail? IEEE Trans. Dielectr. Electr. Insul. 2010, 17, 1385-1395. [CrossRef]

18. Nategh, S.; Barber, D.; Lindberg, D.; Boglietti, A.; Aglen, O. Review and Trends in Traction Motor Design: Primary and Secondary Insulation Systems. In Proceedings of the 2018 XIII International Conference on Electrical Machines (ICEM); 2018; pp. $2607-2612$. [CrossRef]

19. Leuzzi, R.; Monopoli, V.G.; Cupertino, F.; Brando, G.; Dannier, A.; Spina, I.; Pizzo, A.D.; Tommaso, A.O.D.; Castiglia, V.; Schettino, G.; et al. High-Speed Machines: Typologies, Standards, and Operation Under PWM Supply. In Proceedings of the 2018 AEIT International Annual Conference, Bari, Italy, 3-5 October 2018; pp. 1-6. [CrossRef]

20. Sun, P.; Sima, W.; Jiang, X.; Zhang, D.; He, J.; Ye, L. Review of accumulative failure of winding insulation subjected to repetitive impulse voltages. High Volt. 2019, 4, 1-11. [CrossRef]

21. Cavallini, A. Reliability of low voltage inverter-fed motors: What have we learned, perspectives, open points. In Proceedings of the 2017 International Symposium on Electrical Insulating Materials (ISEIM), Toyohashi, Japan, 11-15 September 2017; Volume 1, pp. 13-22.

22. Fabiani, D.; Montanari, G.C.; Contin, A. Aging acceleration of insulating materials for electrical machine windings supplied by PWM in the presence and in the absence of partial discharges. In Proceedings of the ICSD'01-2001 IEEE 7th International Conference on Solid Dielectrics (Cat. No.01CH37117), Eindhoven, The Netherlands, 25-29 June 2001; pp. $283-286$.

23. Fabiani, D.; Montanari, G.C.; Cavallini, A.; Mazzanti, G. Relation between space charge accumulation and partial discharge activity in enameled wires under PWM-like voltage waveforms. IEEE Trans. Dielectr. Electr. Insul. 2004, 11, 393-405. [CrossRef]

24. Persson, E. Transient effects in application of PWM inverters to induction motors. IEEE Trans. Ind. Appl. 1992, 28, 1095-1101. [CrossRef]

25. Bellomo, J.P.; Lebey, T.; Oraison, J.M.; Peltier, F. Characterisation of voltage shapes acting on the insulation of rotating machines supplied by inverters. In Proceedings of the 4th International Conference on Properties and Applications of Dielectric Materials (ICPADM), Brisbane, Australia, 3-8 July 1994; pp. 792-795.

26. Boys, J.T.; Miles, M.J. Empirical thermal model for inverter-driven cage induction machines. IEE Proc. Electr. Power Appl. 1994, 141, 360-372. [CrossRef]

27. Yin, W.; Bultemeier, K.; Barta, D.; Floryan, D. Critical factors for early failure of magnet wires in inverter-fed motor. In Proceedings of the 1995 Conference on Electrical Insulation and Dielectric Phenomena, Virginia Beach, VA, USA, 22-25 October 1995; pp. 258-261.

28. Yin, W.; Bultemeier, K.; Barta, D.; Floryan, D. Dielectric integrity of magnet wire insulations under multi-stresses. In Proceedings of the Electrical/Electronic Insulation Conference, Fort Wayne, IN, USA, September 1995; pp. 257-262. 
29. Oliver, J.A.; Stone, G.C. Implications for the Application of Adjustable Speed Drive Electronics to Motor Stator Winding Insulation. IEEE Electr. Insul. Mag. 1995, 11, 32-36. [CrossRef]

30. Bonnett, A.H. Analysis of the impact of pulse-width modulated inverter voltage waveforms on AC induction motors. IEEE Trans. Ind. Appl. 1996, 32, 386-392. [CrossRef]

31. Skibinski, G.; Erdman, J.; Pankau, J.; Campbell, J. Assessing AC motor dielectric withstand capability to reflected voltage stress using corona testing. In Proceedings of the IAS'96. Conference Record of the 1996 IEEE Industry Applications Conference Thirty-First IAS Annual Meeting, San Diego, CA, USA, 6-10 October 1996; pp. 694-702.

32. Bellomo, J.P.; Lebey, T.; Oraison, J.M.; Peltier, F. Electrical aging of stator insulation of low voltage rotating machines supplied by inverters. In Proceedings of the Conference Record of the 1996 IEEE International Symposium on Electrical Insulation, Montreal, QC, Canada, 16-19 June 1996; pp. 210-213. [CrossRef]

33. Kaufhold, M.; Börner, G.; Eberhardt, M.; Speck, J. Failure mechanism of the interturn insulation of low voltage electric machines fed by pulse-controlled inverters. IEEE Electr. Insul. Mag. 1996, 12, 9-16. [CrossRef]

34. Rehder, R.H.; Draper, R.E.; Moore, B.J. How good is your motor insulation system? IEEE Electr. Insul. Mag. 1996, 12, 8-14. [CrossRef]

35. Divljakovic, V.; Kline, J.; Akers, J.; Theis, K. Multifactor aging of electrical machines energized by standard PWM drives. In Proceedings of the Conference on Electrical Insulation and Dielectric Phenomena-CEIDP'96, Millbrae, CA, USA, 23-23 October 1996; pp. 808-812.

36. Bonnett, A.H. A Comparison between Insulation Systems Available for PWM-Inverter-Fed Motors. IEEE Trans. Ind. Appl. 1997, 33, 1331-1341. [CrossRef]

37. Yin, W. Dielectric properties of an improved magnet wire for inverter-fed motors. IEEE Electr. Insul. Mag. 1997, 13, 17-23. [CrossRef]

38. Hyypio, D.B. Effects of risetime and cable length on motor insulation degradation resulting from operation on PWM voltage source inverters. In Proceedings of the 1997 IEEE International Electric Machines and Drives Conference Record, Milwaukee, WI, USA, 18-21 May 1997; pp. 3-5.

39. Yin, W. Failure mechanism of winding insulations in inverter-fed motors. IEEE Electr. Insul. Mag. 1997, 13, 18-23. [CrossRef]

40. Bell, S.; Sung, J. Insulation of small and medium size motors-IGBT inverter fed. In Proceedings of the 1997 IEEE International Electric Machines and Drives Conference Record, Milwaukee, WI, USA, 18-21 May 1997; pp. 3-5. [CrossRef]

41. Foulon, N.; Lucas, J.; Barre, G.; Mailfert, R.; Enon, J. Investigation of the failure mechanism of insulation subjected to repetitive fast voltage surges. In Proceedings of the Electrical Insulation Conference and Electrical Manufacturing and Coil Winding Conference, Rosemont, IL, USA, 25-25 September 1997; pp. 401-406.

42. Bellomo, J.P.; Olivier, H.; Lebey, T. Lifetime determination of polyimide under square voltage waveforms. In Proceedings of the Electrical Insulation Conference and Electrical Manufacturing and Coil Winding Conference, Rosemont, IL, USA, 25-25 September 1997; pp. 419-423. [CrossRef]

43. Katz, M.; Theis, R.J. New high temperature polyimide insulation for partial discharge resistance in harsh environments. IEEE Electr. Insul. Mag. 1997, 13, 24-30. [CrossRef]

44. Beeckman, R.J.; Harber, J.J.; Wentz, S.J. Studies on magnet wire degradation with inverter driven motors. In Proceedings of the Electrical Insulation Conference and Electrical Manufacturing and Coil Winding Conference, Rosemont, IL, USA, 25-25 September 1997; pp. 383-387.

45. Bell, S.; Sung, J. Will your motor insulation survive a new adjustable frequency drive? In Proceedings of the 1996 IAS Petroleum and Chemical Industry Technical Conference, Philadelphia, PA, USA, 23-25 September 1996; pp. 125-130. [CrossRef]

46. Lebey, T. A theoretical approach of partial discharges under square voltage wave forms. In Proceedings of the Conference Record of the 1998 IEEE International Symposium on Electrical Insulation (Cat. No.98CH36239), Arlington, VA, USA, 7-10 June 1998; pp. 257-260. [CrossRef]

47. Tang, Y. Analysis of steep-fronted voltage distribution and turn insulation failure in inverter-fed form-wound ac motor. IEEE Trans. Ind. Appl. 1998, 34, 1088-1096. [CrossRef]

48. Mbaye, A.; Lebey, T. Analytical approach of PD activity in low voltage motors fed by inverters [adjustable speed drives]. In Proceedings of the ICSD'98-1998 IEEE 6th International Conference on Conduction and Breakdown in Solid Dielectrics (Cat. No.98CH36132), Vasteras, Sweden, 22-25 June 1998; pp. 161-164.

49. Melfi, M.; Jason Sung, A.M.; Bell, S.; Skibinski, G.L. Effect of surge voltage risetime on the insulation of low-voltage machines fed by pwm converters. IEEE Trans. Ind. Appl. 1998, 34, 766-775. [CrossRef]

50. Lebey, T.; Castelan, P.; Montanari, G.C.; Ghinello, I. Influence of PWM-type voltage waveforms on reliability of machine insulation system. In Proceedings of the 8th International Conference on Harmonics and Quality of Power (Cat. No.98EX227), Athens, Greece, 14-16 October 1998; pp. 994-998. [CrossRef]

51. Petrarca, C.; Egiziano, L.; Tucci, V.; Vitelli, M. Investigation on performances of insulation materials for inverter-fed traction motors. In Proceedings of the 1998 Annual Report Conference on Electrical Insulation and Dielectric Phenomena (Cat. No.98CH36257), Atlanta, GA, USA, 25-28 October 1998; Volume 2, pp. 564-567.

52. Stone, G.; Kapler, J. The impact of adjustable speed drive (ASD) voltage surges on motor stator windings. In Proceedings of the 1998 IEEE/PCA Cement Industry Technical Conference. XL Conference Record (98CH36070), Rapid City, SD, USA, 17-21 May 1998; pp. 133-138. [CrossRef] 
53. Stone, G.C.; Campbell, S.R.; Sedding, H.G. Adjustable speed drive surges: how they affect motor stator windings. In Proceedings of the IEEE International Electric Machines and Drives Conference. IEMDC'99 (Cat. No.99EX272), Seattle, WA, USA, 9-12 May 1999; pp. 207-209.

54. Beeckman, R.J. Inverter drive issues and magnet wire responses. In Proceedings of the Electrical Insulation Conference and Electrical Manufacturing and Coil Winding Conference (Cat. No.99CH37035), Cincinnati, OH, USA, 28 October 1999; pp. 139-141.

55. Bellomo, J.P.; Castelan, P.; Lebey, T. The effect of pulsed voltages on dielectric material properties. IEEE Trans. Dielectr. Electr. Insul. 1999, 6, 20-26. [CrossRef]

56. Centurioni, L.; Guastavino, F.; Cerutti, B.; Loffari, V. An experimental optimization of preliminary tests on enameled-copper wires adopted for motor windings of PWM controlled solid state drives. In Proceedings of the 2000 Power Engineering Society Summer Meeting (Cat. No.00CH37134), Seattle, WA, USA, 16-20 July 2000; pp. 2449-2452.

57. Guastavino, F.; Coletti, G.; Cerutti, B.; Torello, E. An experimental study about the weight of the (dv/dt) factor characterizing inverter-like voltages during pre-selection tests on copper enameled wires for adjustable speed drives motors. In Proceedings of the 2000 Power Engineering Society Summer Meeting (Cat. No.00CH37134), Seattle, WA, USA, 16-20 July 2000; pp. $2446-2448$.

58. Hwang, D.-H.; Park, D.-Y.; Kim, Y.-J.; Kim, D.-H.; Koo, J.-Y.; Kim, J.-H. Analysis of insulation characteristics of low-voltage induction motor driven by IGBT PWM inverter. In Proceedings of the Conference Record of the 2000 IEEE International Symposium on Electrical Insulation (Cat. No.00CH37075), Anaheim, CA, USA, 5 April 2000; pp. 17-20.

59. Campbell, S.R.; Stone, G.C. Examples of stator winding partial discharge due to inverter drives. In Proceedings of the Conference Record of the 2000 IEEE International Symposium on Electrical Insulation (Cat. No.00CH37075), Anaheim, CA, USA, 5 April 2000; pp. 231-234.

60. Wang, J.; McInerny, S.; Haskew, T. Insulation fault detection in a PWM controlled induction motor-experimental design and preliminary results. In Proceedings of the Ninth International Conference on Harmonics and Quality of Power (Cat. No.00EX441), Orlando, FL, USA, 1-4 October 2000; pp. 487-492.

61. Hains, A.J. Insulation performance under switched voltage waveforms. Power Eng. J. 2000, 14, 158-163. [CrossRef]

62. Stone, G.; Campbell, S.; Tetreault, S. Inverter-fed drives: which motor stators are at risk? IEEE Ind. Appl. Mag. 2000, 6, 17-22. [CrossRef]

63. Hudon, C.; Amyot, N.; Jean, J. Long term behavior of corona resistant insulation compared to standard insulation of magnet wire. In Proceedings of the Conference Record of the 2000 IEEE International Symposium on Electrical Insulation (Cat. No.00CH37075), Anaheim, CA, USA, 5 April 2000; pp. 13-16.

64. Hudon, C.; Amyot, N.; Lebey, T.; Castelan, P.; Kandev, N. Testing of low-voltage motor turn insulation intended for pulse-width modulated applications. IEEE Trans. Dielectr. Electr. Insul. 2000, 7, 783-789. [CrossRef]

65. Stone, G.C.; Campbell, S.R.; Lloyd, B.A.; Tetreault, S. Which inverter drives need upgraded motor stator windings. In Proceedings of the Record of Conference Papers. Industry Applications Society Forty-Seventh Annual Conference. 2000 Petroleum and Chemical Industry Technical Conference (Cat. No.00CH37112), San Antonio, TX, USA, 3-13 September 2000; pp. 149-154.

66. Fenger, M.; Campbell, S.R.; Gao, G. The impact of surge voltage rise-time on PD inception voltage in random wound motors of different designs. Annu. Rep. 2001, 352-355. [CrossRef]

67. Fenger, M.; Campbell, S.R.; Pedersen, J. Dealing with motor winding problems caused by inverter drives. In Cement Industry Technical Conference IEEE-IAS/PCS 2002. Conference Record (Cat. No.02CH37282); IEEE: Piscataway, NJ, USA, $2002 ;$ pp. 65-76.

68. Kimura, K.; Itaya, S.; Hikita, M. Partial discharge behavior on PI film with microgap under steep-front step voltage. Conf. Rec. IEEE Int. Symp. Electr. Insul. 2002, 4, 1-4. [CrossRef]

69. Candela, R.; Petrarca, C.; Romano, P. Effect of high frequency conducted disturbances on the interturn insulation of an inverter-fed induction motor. In Proceedings of the Conference on Electrical Insulation and Dielectric Phenomena (CEIDP), Annual Report, Albuquerque, NM, USA, 19-22 October 2003; pp. 510-513.

70. Zhou, K.; Wu, G.; Lei, K.; Wu, J.; Liu, J. Aging Time Effect on PD Characteristics under Continuous Pulse Voltage. In Proceedings of the 2007 IEEE International Conference on Solid Dielectrics, Winchester, UK, 8-13 July 2007; pp. 616-618.

71. Liu, X.; Wu, G.; Tong, L.; Lin, T.; Zhang, G. Influence of impulse frequency on partial discharge under PWM. In Proceedings of the Conference Record of the 2006 IEEE International Symposium on Electrical Insulation, Winchester, UK, 8-13 July 2007; pp. 241-244.

72. Vaclav, M.; Josef, P.; Pavel, T.; Oldrich, T. Pulse voltage and its aging effect on PD characteristics of slot insulation. In Proceedings of the Conference Record of IEEE International Symposium on Electrical Insulation, Vancouver, BC, Canada, 9-12 June 2008; pp. $575-578$.

73. Obata, K.; Takeuchi, R.; Shimozono, T.; Kikuchi, H. Partial Discharge under pulse voltage with narrow pulse width. IEEE J Trans. Fundam. Mater. 2008, 128, 298-306. [CrossRef]

74. Florkowska, B.; Zydroń, P.; Roehrich, J.; Florkowski, M. Performance of cables and machines insulation at various parameters of impulse stimulus. In Proceedings of the 2010 International Conference on High Voltage Engineering and Application, New Orleans, LA, USA, 11-14 October 2010; pp. 144-147.

75. Wu, G.; Cao, K.; Luo, Y.; Gao, B.; Wang, P.; Zhang, Y.; Xu, H. Partial discharge characteristics of interturn insulation used for inverter-fed traction motor under bipolar impulses. Sci. China Technol. Sci. 2012, 55, 2346-2354. [CrossRef]

76. Zhou, K.; Wan, L.; Li, X. Aging Characteristics of Inter-turn Insulation of Form-wound Stator Windings of Inverter-fed AC Motors. Electr. Power Components Syst. 2013, 41, 1280-1293. [CrossRef] 
77. Luo, Y.; Wu, G.; Liu, J.; Zhu, G.; Wang, P.; Peng, J.; Cao, K. PD characteristics and microscopic analysis of polyimide film used as turn insulation in inverter-fed motor. IEEE Trans. Dielectr. Electr. Insul. 2014, 21, 2237-2244. [CrossRef]

78. Hayakawa, N.; Inano, H.; Inuzuka, K.; Morikawa, M.; Okubo, H. Partial Discharge Propagation and Degradation Characteristics of Magnet Wire for Inverter-Fed Motor under Surge Voltage Application. In Proceedings of the 2006 IEEE Conference on Electrical Insulation and Dielectric Phenomena, Kansas City, MO, USA, 15-18 October 2006; pp. 565-568.

79. Morikawa, M.; Hayakawa, N.; Okubo, H. Partial discharge inception and degradation characteristics of inverter-fed motor sample under surge voltage condition. In Proceedings of the CEIDP'05. 2005 Annual Report Conference on Electrical Insulation and Dielectric Phenomena, Nashville, TN, USA, 16-19 October 2005; pp. 426-429.

80. Okubo, H.; Hayakawa, N.; Montanari, G.C. Technical Development on Partial Discharge Measurement and Electrical Insulation Techniques for Low Voltage Motors Driven by Voltage Inverters. IEEE Trans. Dielectr. Electr. Insul. 2007, 14, 1516-1530. [CrossRef]

81. Hayakawa, N.; Shimizu, F.; Peng, X.; Okubo, H. Partial discharge inception voltage for magnet wire of inverter-fed motors under surge voltage application. In Proceedings of the 2010 Annual Report Conference on Electrical Insulation and Dielectic Phenomena, West Lafayette, IN, USA, 17-20 October 2010; pp. 1-4.

82. Wang, P.; Cavallini, A.; Montanari, G.C. The influence of impulsive voltage frequency on PD features in turn insulation of inverter-fed motors. In Proceedings of the 2014 IEEE Conference on Electrical Insulation and Dielectric Phenomena (CEIDP), Des Moines, IA, USA, 19-22 October 2014; pp. 35-38.

83. Wang, P.; Cavallini, A. The influence of repetitive square wave voltage parameters on PD statistical features. In Proceedings of the 2013 Annual Report Conference on Electrical Insulation and Dielectric Phenomena, Chenzhen, China, 20-23 October 2013; pp. $1282-1285$.

84. Wang, P.; Cavallini, A.; Montanari, G.C. Characteristics of PD under square wave voltages and their influence on motor insulation endurance. IEEE Trans. Dielectr. Electr. Insul. 2015, 22, 3079-3086. [CrossRef]

85. Wang, P.; Montanari, G.C.; Cavallini, A. Partial Discharge Phenomenology and Induced Aging Behavior in Rotating Machines Controlled by Power Electronics. IEEE Trans. Ind. Electron. 2014, 61, 7105-7112. [CrossRef]

86. Wang, P.; Wu, G.; Gao, B.; Luo, Y.; Cao, K. Study of partial discharge characteristics at repetitive square voltages based on UHF method. Sci. China Technol. Sci. 2013, 56, 262-270. [CrossRef]

87. Wang, P.; Wu, G.; Luo, Y.; Zhu, G. Effect of repetitive square voltage frequency on partial discharge features. Sci. China Technol. Sci. 2013, 56, 1313-1321. [CrossRef]

88. Wang, P.; Cavallini, A.; Montanari, G.C. The effects of square wave voltage rise time on PD statistics in time and frequency domain. In Proceedings of the 2015 IEEE Electrical Insulation Conference (EIC), Seattle, WA, USA, 7-10 June 2015; pp. $262-265$.

89. Wang, P.; Cavallini, A.; Montanari, G.C.; Wu, G. Effect of rise time on PD pulse features under repetitive square wave voltages. IEEE Trans. Dielectr. Electr. Insul. 2013, 20, 245-254. [CrossRef]

90. Hayakawa, N.; Okubo, H. Partial discharge characteristics of inverter-fed motor coil samples under AC and surge voltage conditions. IEEE Electr. Insul. Mag. 2005, 21, 5-10. [CrossRef]

91. Takino, T.; Murakami, Y.; Hozumi, N.; Nagao, M. Evaluation of partial discharge under inverter surge application using current waveform. In Proceedings of the 2010 Annual Report Conference on Electrical Insulation and Dielectic Phenomena, West Lafayette, IN, USA, 17-20 October 2010; pp. 1-4.

92. Stone, G.C.; Culbert, I. Partial discharge testing of random wound stators during short risetime voltage surges. In Proceedings of the 2009 IEEE Electrical Insulation Conference, Montreal, QC, Canada, 31 May-3 June 2009; pp. 188-191.

93. Kimura, K.; Ushirone, S.; Koyanagi, T.; Hikita, M. PDIV characteristics of twisted-pair of magnet wires with repetitive impulse voltage. IEEE Trans. Dielectr. Electr. Insul. 2007, 14, 744-750. [CrossRef]

94. Hayakawa, N.; Morikawa, M.; Okubo, H. Partial discharge inception and propagation characteristics of magnet wire for inverter-fed motor under surge voltage application. IEEE Trans. Dielectr. Electr. Insul. 2007, 14, 39-45. [CrossRef]

95. Hayakawa, N.; Shimizu, F.; Okubo, H. Estimation of partial discharge inception voltage of magnet wires under inverter surge voltage by volume-time theory. IEEE Trans. Dielectr. Electr. Insul. 2012, 19, 550-557. [CrossRef]

96. He, J.; Wu, G.; Gao, B.; Wu, J. Study on aging characteristics for inverter-fed traction Motor inter-turn insulation based on analysis of dielectric characteristic parameters. In Proceedings of the 2007 Annual Report-Conference on Electrical Insulation and Dielectric Phenomena, Vancouver, BC, Canada, 14-17 October 2007; pp. 81-84.

97. Fenger, M.; Stone, G.C. Progress in understanding the nature of PD in stators created by inverter drives. In Proceedings of the Electrical Insulation Conference and Electrical Manufacturing and Coil Winding Technology Conference (Cat. No.03CH37480), Indianapolis, IN, USA, 25 September 2003; pp. 363-367.

98. Florkowska, B.; Florkowski, M.; Roehrich, J.; Zydroń, P. Modelling of degradation process of electrical insulation systems due to inverter pulses. Przegląd Elektrotechniczny 2014, 90, 85-89.

99. Toliyat, H.A.; Kliman, G.B. Handbook of Electric Motors, 2rd ed.; CRC Press: New York, NY, USA, $2004 ;$ ISBN 9780824741051.

100. Grubic, S.; Aller, J.M.; Lu, B.; Habetler, T.G. A Survey on Testing and Monitoring Methods for Stator Insulation Systems of Low-Voltage Induction Machines Focusing on Turn Insulation Problems. IEEE Trans. Ind. Electron. 2008, 55, 4127-4136. [CrossRef]

101. Thomson, W.T.; Morrison, D. On-line diagnosis of stator shorted turns in mains and inverter fed low voltage induction motors. In Proceedings of the 2002 International Conference on Power Electronics, Machines and Drives (Conf. Publ. No. 487), Santa Fe, NM, USA, 4-7 June 2002; pp. 122-127. 
102. Werynski, P.; Corton, R.; Roger, D.; Brudny, J.F. On-line monitoring of Insulation Aging in AC Motors Fed by PWM Inverters. In Proceedings of the IEEE International Conference on Electric Machines and Drives, San Antonio, TX, USA, 15-15 May 2005; pp. 1942-1948.

103. Vogelsberger, M.A.; Zoeller, C.; Nussbaumer, P.; Votzi, H.; Ertl, H.; Wolbank, T.M. Online insulation condition monitoring of ac machines using ultra-fast inverter switching transition based on new semi-conductor materials. In Proceedings of the PCIM Europe 2014; International Exhibition and Conference for Power Electronics, Intelligent Motion, Renewable Energy and Energy Management, Nuremberg, Germany, 20-22 May 2014; pp. 1-7.

104. Zhang, P.; Younsi, K.; Neti, P. A Novel Online Stator Ground-Wall Insulation Monitoring Scheme for Inverter-Fed AC Motors. IEEE Trans. Ind. Appl. 2015, 51, 2201-2207. [CrossRef]

105. Tsyokhla, I.; Griffo, A.; Wang, J. On-line monitoring of winding insulation health using high frequency common mode voltage from PWM. In Proceedings of the 2015 IEEE International Electric Machines \& Drives Conference (IEMDC), Coeur d'Alene, ID, USA, 10-13 May 2015; pp. 1433-1439.

106. Kato, T.; Nagata, M.; Maki, K.; Kojima, H.; Souma, K.; Iwaji, Y. Motor Insulation Aging Diagnosis with Pre-Installed Current Sensors for Inverter Control. In Proceedings of the 2018 XIII International Conference on Electrical Machines (ICEM), Alexandroupoli, Greece, 3-6 September 2018; pp. 1894-1899.

107. Tsyokhla, I.; Griffo, A.; Wang, J. On-Line Motor Insulation Capacitance Monitoring Using Low-Cost Sensors. In Proceedings of the 2019 IEEE Energy Conversion Congress and Exposition (ECCE), Baltimore, MD, USA, 29 September-3 October 2019; pp. 6996-7003.

108. Nussbaumer, P.; Mitteregger, A.; Wolbank, T.M. Online detection of insulation degradation in inverter fed drive systems based on high frequency current sampling. In Proceedings of the IECON 2011-37th Annual Conference of the IEEE Industrial Electronics Society, Melbourne, VIC, Australia, 7-10 November 2011; pp. 1954-1959.

109. Nussbaumer, P.; Wolbank, T.M.; Vogelsberger, M.A. Separation of disturbing influences on induction machine's high-frequency behavior to ensure accurate insulation condition monitoring. In Proceedings of the 2013 Twenty-Eighth Annual IEEE Applied Power Electronics Conference and Exposition (APEC), Long Beach, CA, USA, 17-21 March 2013; pp. 1158-1163.

110. Nussbaumer, P.; Vogelsberger, M.A.; Wolbank, T.M. Exploitation of induction machine's high-frequency behavior for online insulation monitoring. In Proceedings of the 2013 9th IEEE International Symposium on Diagnostics for Electric Machines, Power Electronics and Drives (SDEMPED), Valencia, Spain, 27-30 August 2013; pp. 579-585.

111. Nussbaumer, P.; Wolbank, T.M.; Vogelsberger, M.A. Sensitivity analysis of insulation state indicator in dependence of sampling rate and bit resolution to define hardware requirements. In Proceedings of the 2013 IEEE International Conference on Industrial Technology (ICIT), Cape Town, South Africa, 25-28 February 2013; pp. 392-397.

112. Nussbaumer, P.; Vogelsberger, M.A.; Wolbank, T.M. Induction Machine Insulation Health State Monitoring Based on Online Switching Transient Exploitation. IEEE Trans. Ind. Electron. 2015, 62, 1835-1845. [CrossRef]

113. Cash, M.A.; Habetler, T.G. Insulation failure detection in the stator windings of ASD-driven induction machines using standard deviation of line currents. In Proceedings of the Conference Record of 1998 IEEE Industry Applications Conference. Thirty-Third IAS Annual Meeting (Cat. No.98CH36242), St. Louis, MO, USA, 12-15 October 1998; pp. $299-303$.

114. Bolgova, V.; Lefebvre, S.; Hlioui, S.; Boucenna, N.; Costa, F.; Leonov, A. Development of testing methods for winding turn-to-turn insulation of low voltage motors fed by PWM converters. In Proceedings of the 2017 19th European Conference on Power Electronics and Applications (EPE'17 ECCE Europe), Warsaw, Poland, 11-14 September 2017; pp. 1-10.

115. Yang, J.; Lee, S.B.; Yoo, J.; Lee, S.; Oh, Y.; Choi, C. A Stator Winding Insulation Condition Monitoring Technique for Inverter-Fed Machines. IEEE Trans. Power Electron. 2007, 22, 2026-2033. [CrossRef]

116. Yang, J.; Cho, J.; Lee, S.B.; Yoo, J.-Y.; Kim, H.D. An advanced stator winding insulation quality assessment technique for inverter-fed machines. IEEE Trans. Ind. Appl. 2008, 44, 555-564. [CrossRef]

117. Yang, J.; Cho, J.; Lee, S.B.; Jung, H.; Park, Y. An inverter-embedded stator winding insulation quality assessment technique for AC machines. In Proceedings of the 2008 International Conference on Condition Monitoring and Diagnosis, Beijing, China, 21-24 April 2008; pp. 143-150.

118. Yang, J.; Kang, T.; Kim, B.; Lee, S.B.; Yoon, Y.; Kang, D.; Cho, J.; Kim, H. Experimental evaluation of using the surge PD test as a predictive maintenance tool for monitoring turn insulation quality in random wound AC motor stator windings. IEEE Trans. Dielectr. Electr. Insul. 2012, 19, 53-60. [CrossRef]

119. Lee, S.B.; Yang, J.; Hong, J.; Yoo, J.; Kim, B.; Lee, K.; Yun, J.; Kim, M.; Lee, K.; Wiedenbrug, E.J.; et al. A New Strategy for Condition Monitoring of Adjustable Speed Induction Machine Drive Systems. IEEE Trans. Power Electron. 2011, 26, 389-398. [CrossRef]

120. Tozzi, M.; Cavallini, A.; Montanari, G.C. Monitoring off-line and on-line PD under impulsive voltage on induction motors-Part 1: standard procedure. IEEE Electr. Insul. Mag. 2010, 26, 16-26. [CrossRef]

121. Tozzi, M.; Cavallini, A.; Montanari, G.C. Monitoring off-line and on-line PD under impulsive voltage on induction motors-Part 3: Criticality. IEEE Electr. Insul. Mag. 2011, 27, 26-33. [CrossRef]

122. Tozzi, M.; Cavallini, A.; Montanari, G.C. Monitoring off-line and on-line PD under impulsive voltage on induction motors-Part 2: testing*. IEEE Electr. Insul. Mag. 2011, 27, 14-21. [CrossRef]

123. Stone, G.C.; Culbert, I.; Campbell, S.R. Progress in on-line measurement of PD in motors fed by voltage source PWM drives. In Proceedings of the 2014 IEEE Electrical Insulation Conference (EIC), Philadelphia, PA, USA, 8-11 June 2014; pp. 172-175. 
124. Busch, M.K.; Hilfert, S. An approach for measuring partial discharges in PWM inverter driven induction machines. In Proceedings of the Conference Record of the 2000 IEEE International Symposium on Electrical Insulation (Cat. No.00CH37075), Anaheim, CA, USA, 5 April 2000; pp. 227-230.

125. Martínez-Tarifa, J.M.; Robles, G. Partial discharges measurement during under-damped steep-fronted overvoltages. In Proceedings of the 2020 IEEE International Instrumentation and Measurement Technology Conference (I2MTC), Dubrovnik, Croatia, 25-28 May 2020; pp. 1-5.

126. Niskanen, V.; Ahola, J.; Lehtinen, P. Verification of the applicability of an RF-signal-based detection method for partial discharges on inverter-fed random wound stator windings in a low-voltage induction motor. In Proceedings of the 2013 15th European Conference on Power Electronics and Applications (EPE), Lille, France, 2-6 September 2013; pp. 1-11.

127. Niskanen, V.; Ahola, J.; Lehtinen, P. Study of applicability of RF based measurement method for partial discharge detection in stator windings of inverter-fed low voltage induction motors. In Proceedings of the Ninth International Conference on Condition Monitoring and Machinery Failure Prevention Technologies, London, UK, 12-14 June 2012; pp. 896-904.

128. Ortega, D.F.; Castelli-Dezza, F. On line partial discharges test on rotating machines supplied by IFDs. In Proceedings of the XIX International Conference on Electrical Machines-ICEM 2010, Rome, Italy, 6-8 September 2010; pp. 1-4.

129. Stone, G.C.; Culbert, I.; Sedding, H.G. Case studies in on-line measurement of PD in motors fed by voltage source PWM drives. In Proceedings of the 2015 IEEE 11th International Conference on the Properties and Applications of Dielectric Materials (ICPADM), Sydney, NSW, Australia, 19-22 July 2015; pp. 248-251.

130. Bidan, P.; Lebey, T.; Neacsu, C. Development of a new off-line test procedure for low voltage rotating machines fed by adjustable speed drives (ASD). IEEE Trans. Dielectr. Electr. Insul. 2003, 10, 168-175. [CrossRef]

131. Neacsu, C.; Bidan, P.; Lebey, T. Off line measurements of partial discharges in turn insulation of low voltage rotating machines. In Proceedings of the Conference Record of the 2000 IEEE International Symposium on Electrical Insulation, Insulation, Anaheim, CA, USA, 5-5 April 2000; pp. 235-238.

132. Cavallini, A.; Montanari, G.C.; Contin, A.; Qinxue, Y. Techniques for off-line measurement and analysis of PD pulses in inverterfed induction motors. In Proceedings of the 7th International Conference on Properties and Applications of Dielectric Materials, 2003, Nagoya, Japan, 1-5 June 2003; pp. 1071-1075.

133. Collin, P.; Malec, D.; Lefevre, Y. About the relevance of using Paschen's criterion for partial discharges inception voltage (PDIV) estimation when designing the electrical insulation system of inverter fed motors. In Proceedings of the 2019 IEEE Electrical Insulation Conference (EIC), Calgary, AB, Canada, 16-19 June 2019; pp. 513-516.

134. Hiroshima, S.; Hirose, T.; Sakai, M.; Hatano, H.; Yoshimitsu, T.; Sakurai, T.; Ikegami, T. Off-line and on-line detection of PD in inverter-fed random-wound motor considering IEC technical specifications. In Proceedings of the 2012 Annual Report Conference on Electrical Insulation and Dielectric Phenomena, Montreal, QC, Canada, 14-17 October 2012; pp. 72-75.

135. Tozzi, M.; Montanari, G.C.; Fabiani, D.; Cavallini, A.; Gao, G. Off-line and on-line PD measurements on induction motors fed by power electronic impulses. In Proceedings of the 2009 IEEE Electrical Insulation Conference, Montreal, QC, Canada, 31 May-3 June 2009; pp. 420-424.

136. Filliben, S. Advantages of polyimide corona resistant film under high frequency testing. In Proceedings of the Electrical Insulation Conference and Electrical Manufacturing and Coil Winding Technology Conference (Cat. No.03CH37480), Indianapolis, IN, USA, 25 September 2003; pp. 627-631.

137. Tarifa, J.M.M.; Feito, J.S.; Duarte, H.A. Turn to turn insulation ageing diagnosis using frequency response analysis. In Proceedings of the 2004 IEEE International Conference on Solid Dielectrics (ICSD 2004), Toulouse, France, 5-9 July 2004 ; pp. 880-883.

138. Haq, S.U.; Jayaram, S.H.; Cherney, E.A. Degradation of turn insulation subjected to fast repetitive voltage pulses. In Proceedings of the Proceedings Electrical Insulation Conference and Electrical Manufacturing Expo, Indianapolis, IN, USA, 23-26 October 2005; pp. 163-166.

139. Tong, L.; Wu, G.; Zhang, G.; Lin, T. Study on breakdown of magnet wire used in AC traction motor. In Proceedings of the 2005 International Symposium on Electrical Insulating Materials (ISEIM 2005), Kitakyushu, Japan, 5-9 June 2005; pp. $172-175$.

140. Gao, B.; Wu, G.N.; He, J.Y.; Lei, K.G. Investigation on aging mechanism of winding insulation used in inverter-fed traction motors. In Proceedings of the 2007 Annual Report-Conference on Electrical Insulation and Dielectric Phenomena, Vancouver, BC, Canada, 14-17 October 2007; pp. 107-111.

141. Espino-Cortes, F.P.; Zamorano, P.G.; Rosario, A.R. Effect of voltage distortion on stress grading coatings working at high fundamental frequency. In Proceedings of the 2007 Electrical Insulation Conference and Electrical Manufacturing Expo, Nashville, TN, USA, 22-24 October 2007; pp. 159-163.

142. Wu, G.N.; Wu, J.D.; Zhou, L.R.; Gao, B.; Zhou, K.; Guo, X.X.; Cao, K.J. Microscopic view of aging mechanism of polyimide film under pulse voltage in presence of partial discharge. IEEE Trans. Dielectr. Electr. Insul. 2010, 17, 125-132. [CrossRef]

143. Florkowska, B.; Florkowski, M.; Roehrich, J.; Zydron, P. The influence of PWM stresses on degradation processes in electrical insulation systems. In Proceedings of the 2010 Annual Report Conference on Electrical Insulation and Dielectic Phenomena, West Lafayette, IN, USA, 17-20 October 2010; pp. 1-4.

144. Florkowska, B.; Zydron, P.; Florkowski, M. Effects of inverter pulses on the electrical insulation system of motors. In Proceedings of the 2011 IEEE International Symposium on Industrial Electronics, Gdansk, Poland, 27-30 June 2011; pp. 573-578. 
145. Luo, Y.; Wu, G.N.; Wang, P.; Cao, K.J.; Cui, Y. Insulation failure of inter-turn insulation in inverter-fed traction motor. In Proceedings of the 2012 Annual Report Conference on Electrical Insulation and Dielectric Phenomena, Montreal, QC, Canada, 14-17 October 2012; pp. 831-834.

146. Luo, Y.; Wu, G.N.; Liu, J.W.; Peng, J.; Gao, G.Q.; Zhu, G.Y.; Wang, P.; Cao, K.J. Microscopic degradation mechanism of polyimide film caused by surface discharge under bipolar continuous square impulse voltage. Chinese Phys. B. 2014, 23. [CrossRef]

147. Hwang, D.-H.; Kim, Y.-J.; Bae, S.-W.; Kim, D.-H.; Lee, I.-W. Experimental comparison of insulation systems for IGBT PWM inverter-fed low-voltage induction motors. In Proceedings of the 2002 IEEE 33rd Annual IEEE Power Electronics Specialists Conference (Cat. No.02CH37289), Cairns, QLD, Australia, 23-27 June 2002; pp. 973-978.

148. Hwang, D.-H.; Lee, K.-C.; Kim, Y.-J.; Lee, I.-W.; Lim, T.-H.; Kim, D.-H. Accessing the insulation characteristics for stator windings of low-voltage induction motors for adjustable-speed drive applications. In Proceedings of the 38th IAS Annual Meeting on Conference Record of the Industry Applications Conference, Salt Lake City, UT, USA, 12-16 October 2003; pp. $432-438$.

149. Hwang, D.-H.; Park, D.-Y.; Kim, Y.-J.; Kim, D.-H.; Koo, J.-Y.; Hur, I.-G. Analysis of insulation characteristics of PWM inverter-fed induction motors. In Proceedings of the 2001 IEEE International Symposium on Industrial Electronics (ISIE) (Cat. No.01TH8570), Pusan, Korea, 12-16 June 2001; pp. 477-481.

150. Hwang, D.-H.; Park, D.-Y.; Kim, Y.-J.; Lee, Y.-H.; Kim, D.-H.; Lee, I.-W.; Hur, I.-G. A comparison with insulation system for PWM-inverter-fed induction motors. In Proceedings of the ICEMS'2001 5th International Conference on Electrical Machines and Systems (IEEE Cat. No.01EX501), Shenyang, China, 18-20 August 2001; pp. 72-75.

151. Wang, P.; Cavallini, A.; Montanari, G.C. The effect of impulsive voltage rise time on insulation endurance of inverter-fed motors. In Proceedings of the 2015 IEEE 11th International Conference on the Properties and Applications of Dielectric Materials (ICPADM), Sydney, NSW, Australia, 19-22 July 2015; pp. 84-87.

152. Wang, P.; Cavallini, A.; Montanari, G.C. Endurance testing of rotating machines insulation systems: Do sinusoidal and square voltage waveforms provide comparable results? In Proceedings of the 2013 IEEE International Conference on Solid Dielectrics (ICSD), Bologna, Italy, 8 October 2013; pp. 310-313.

153. Wang, P.; Cavallini, A.; Montanari, G.C. The influence of repetitive square wave voltage parameters on enameled wire endurance. IEEE Trans. Dielectr. Electr. Insul. 2014, 21, 1276-1284. [CrossRef]

154. Coletti, G.; Guastavino, F.; Torello, E. Influence of different square voltage waveforms on the partial discharges behavior during tests on twisted pair specimens. In Proceedings of the Conference Record of the the 2002 IEEE International Symposium on Electrical Insulation (Cat. No.02CH37316), Boston, MA, USA, 7-10 April 2002; pp. 36-39.

155. Guastavino, F.; Cerutti, B.; Bona, S.; Colombo, C.; Mariani, A. High frequency and high voltage tests on electric motors stator windings. In Proceedings of the ICSD'01-2001 IEEE 7th International Conference on Solid Dielectrics (Cat. No.01CH37117), Eindhoven, Netherlands, 25-29 June 2001; pp. 268-271.

156. Guastavino, F.; Coletti, G.; Cerutti, B. Enamelled twisted pairs specimens: quasi-square voltage rise time influence on lifetests values. In Proceedings of the 2001 Annual Report Conference on Electrical Insulation and Dielectric Phenomena (Cat. No.01CH37225), Kitchener, ON, Canada, 14-17 October 2001; pp. 197-200.

157. Guastavino, F.; Coletti, G.; Dardano, A.; Torello, E. Life tests on twisted pairs subjected to PWM-like voltages. In Proceedings of the 2004 IEEE International Conference on Solid Dielectrics (ICSD), Toulouse, France, 5-9 July 2004; pp. 860-863.

158. Guastavino, F.; Coletti, G.; Torello, E. Twisted pairs specimens subjected to several waveform voltages in presence of partial discharges. In Proceedings of the Annual Report Conference on Electrical Insulation and Dielectric Phenomena, Cancun, Mexico, 20-24 October 2002; pp. 450-453.

159. Guastavino, F.; Cordano, D.; Torello, E.; Secondo, G. Electrical aging tests on different kind of insulating systems adopted for induction stator motor. In Proceedings of the 2015 IEEE Conference on Electrical Insulation and Dielectric Phenomena (CEIDP), Ann Arbor, MI, USA, 18-21 October 2015; pp. 808-811.

160. Guastavino, F.; Dardano, A. Life tests on twisted pairs in presence of partial discharges: influence of the voltage waveform. IEEE Trans. Dielectr. Electr. Insul. 2012, 19, 45-52. [CrossRef]

161. Guastavino, F.; Porcile, F.; Ratto, A.; Cordano, D.; Secondo, G. Electrical aging test and repetitive partial discharge inception voltage on random wire wound winding insulation. In Proceedings of the 2014 IEEE Conference on Electrical Insulation and Dielectric Phenomena (CEIDP), Des Moines, IA, USA, 19-22 October 2014; pp. 510-513.

162. Guastavino, F.; Porcile, F.; Ratto, A.; Giovanna, L.D.; Secondo, G. Electrical ageing test on random wire wound stator insulation applying voltage pulses. In Proceedings of the 2013 Annual Report Conference on Electrical Insulation and Dielectric Phenomena, Chenzhen, China, 20-23 October 2013; pp. 206-209.

163. Guastavino, F.; Ratto, A.; Dardano, A.; Torello, E.; Biondi, G.; Loggi, G.; Ceci, A. Comparison among the PD resistance behavior of different enameled wires when subjected to PWM voltage. In Proceedings of the 2011 Annual Report Conference on Electrical Insulation and Dielectric Phenomena, Cancun, Mexico, 16-19 October 2011; pp. 314-317.

164. Guastavino, F.; Ratto, A.; Squarcia, S.; Torello, E. Electro-thermal aging tests on different kinds of enamelled wires. In Proceedings of the 2010 10th IEEE International Conference on Solid Dielectrics, Potsdam, Germany, 4-9 July 2010; pp. 1-4.

165. Guastavino, F.; Ratto, A.; Torello, E.; Biondi, G. Aging Tests on Nanostructured Enamels for Winding Wire Insulation. IEEE Trans. Ind. Electron. 2014, 61, 5550-5557. [CrossRef] 
166. Guastavino, F.; Torrello, E.; del Casale, M.D.L.; Egiziano, L. Voltage distortion effects on insulation systems behaviour in ASD motors. In Proceedings of the 2003 Annual Report Conference on Electrical Insulation and Dielectric Phenomena, Albuquerque, NM, USA, 19-22 October 2003; pp. 608-611.

167. Cavallini, A.; Montanari, G.C.; Fabiani, D.; Tozzi, M. The influence of PWM voltage waveforms on induction motor insulation systems: Perspectives for the end user. In Proceedings of the 8th IEEE Symposium on Diagnostics for Electrical Machines, Power Electronics \& Drives, Bologna, Italy, 5-8 September 2011; pp. 288-293.

168. Melfi, M.J. Low-Voltage PWM inverter-fed motor insulation issues. IEEE Trans. Ind. Appl. 2006, 42, 128-133. [CrossRef]

169. Stone, G.C.; Culbert, I.M.; Lloyd, B.A. Stator insulation problems associated with low voltage and medium voltage PWM drives. In Proceedings of the 2007 IEEE Cement Industry Technical Conference Record, Charleston, SC, USA, 29 April-2 May 2007; pp. 187-192.

170. Divljakovic, V.; Kline, J.; Barta, D.; Floryan, D. Aging of magnetic wire in the presence of variable frequency, high rise time and high voltage pulses. In Proceedings of the IEEE Conference on Electrical Insulation and Dielectric Phenomena-(CEIDP'94), Arlington, TX, USA, 23-26 October 1994; pp. 391-399.

171. Grzybowski, S.; Bandaru, S.; Kota, N.; King, C.F. Lifetime characteristics of magnet wires under pulse voltage [wire insulation multistress effects]. In Proceedings of the 17th Annual Meeting of the IEEE Lasers and Electro-Optics Society, 2004. LEOS 2004, Boulder, CO, USA, 20-20 October 2004; pp. 145-148.

172. Bocek, V.; Kucerova, E.; Mentlik, V.; Sebik, P.; Trnka, P. Reliability of the adjustable speed drives in power electronic waveform environment. In Proceedings of the Annual Report-Conference on Electrical Insulation and Dielectric Phenomena, CEIDP, Nashville, TN, USA, 16-19 October 2005; pp. 241-244.

173. Qiang, Y.; Guangning, W.; Qian, P.; Bing, A.; Changhong, H.; Mingli, D. Research on electrical aging lifetime model of insulation material under high voltage square impulses for inverter-fed motors. In Proceedings of the 2008 International Conference on Condition Monitoring and Diagnosis, Beijing, China, 21-24 April 2008; pp. 259-263.

174. Gao, B.; Wu, G.; Zhou, L.; Cao, K.; Luo, Y. Research on aging characteristics of twisted pair based on dielectric loss under high frequency pulse voltage. In Proceedings of the 2009 IEEE 9th International Conference on the Properties and Applications of Dielectric Materials, Harbin, China, 19-23 July 2009; pp. 392-395.

175. Lahoud, N.; Faucher, J.; Malec, D.; Maussion, P. Electrical Aging of the Insulation of Low-Voltage Machines: Model Definition and Test With the Design of Experiments. IEEE Trans. Ind. Electron. 2013, 60, 4147-4155. [CrossRef]

176. Lahoud, N.; Nguyen, M.Q.; Maussion, P.; Malec, D.; Mary, D. Lifetime model of the inverter-fed motors secondary insulation by using a design of experiments. IEEE Trans. Dielectr. Electr. Insul. 2015, 22, 3170-3176. [CrossRef]

177. Koltunowicz, T.L.; Bajracharya, G.; Djairam, D.; Smit, J.J. Exploring the feasibility of an aging model for paper insulation based on the repetition frequency of transients. In Proceedings of the 2010 IEEE International Symposium on Electrical Insulation, San Diego, CA, USA, 6-9 June 2010; pp. 1-5.

178. Kaijiang, C.; Guangning, W.; Liren, Z.; Xiaoxia, G.; Kegang, L.; Bo, G. Insulation life-span models for electrical and thermal aging under continuous high square impulses voltage. In Proceedings of the 2009 IEEE 9th International Conference on the Properties and Applications of Dielectric Materials, Harbin, China, 19-23 July 2009; pp. 285-288.

179. Cui, Y.; Wu, G.; Cao, K.; Luo, Y. Life models of polyimide film under combined thermal and electrical stresses used in inverter-fed traction motor. In Proceedings of the 2011 Annual Report Conference on Electrical Insulation and Dielectric Phenomena, Cancun, Mexico, 16-19 October 2011; pp. 80-83.

180. Arora, T.G.; Aware, M.V.; Tutakne, D.R. Fuzzy Logic-based Electrothermal Life Model for Inverter-fed Induction Motor Insulation. Electr. Power Components Syst. 2015, 43, 298-308. [CrossRef]

181. Arora, T.G.; Aware, M.V. Life Model for PWM Controlled Induction Motor Insulation using Design of Experiments Method. Electr. Power Components Syst. 2019, 47, 153-163. [CrossRef]

182. Szczepanski, M.; Malee, D.; Maussion, P.; Petitgas, B.; Manfé, P. Prediction of the lifespan of enameled wires used in low voltage inverter-fed motors by using the Design of Experiments (DoE). In Proceedings of the 2017 IEEE Industry Applications Society Annual Meeting, Cincinnati, OH, USA, 1-5 October 2017; pp. 1-6.

183. Szczepanski, M.; Malec, D.; Maussion, P.; Petitgas, B.; Manfé, P. Use of Design of Experiments (DoE) predictive models as a method of comparison of enameled wires used in low voltage inverter-fed motors. In Proceedings of the 2018 IEEE Industry Applications Society Annual Meeting (IAS), Portland, OR, USA, 23-27 September 2018; pp. 1-8.

184. Szczepanski, M.; Malec, D.; Maussion, P.; Manfé, P. Design of Experiments Predictive Models as a Tool for Lifespan Prediction and Comparison for Enameled Wires Used in Low-Voltage Inverter-Fed Motors. IEEE Trans. Ind. Appl. 2020, 56, 3100-3113. [CrossRef]

185. Cavallini, A.; Fabiani, D.; Montanari, G.C. Power electronics and electrical insulation systems—part 2: life modeling for insulation design. IEEE Electr. Insul. Mag. 2010, 26, 33-39. [CrossRef]

186. Cui, Y.; Wu, G.N.; Luo, Y.; Cao, K.J. Multifactor Stress Life Model of Polyimide Film Used in Inverter-Fed Traction Motors. In Proceedings of the Applied Mechanics and Materials, Taichung, Taiwan, 11-13 December 2011; pp. $239-243$.

187. Maussion, P.; Picot, A.; Chabert, M.; Malec, D. Lifespan and aging modeling methods for insulation systems in electrical machines: A survey. In Proceedings of the 2015 IEEE Workshop on Electrical Machines Design, Control and Diagnosis (WEMDCD), Turin, Italy, 26-27 March 2015; pp. 279-288. 
188. Schemmel, F.; Bauer, K.; Kaufhold, M. Reliability and statistical lifetime-prognosis of motor winding insulation in low-voltage power drive systems. IEEE Electr. Insul. Mag. 2009, 25, 6-13. [CrossRef]

189. Montanari, G.C.; Hebner, R.; Seri, P.; Ghosh, R. Noise rejection and partial discharge identification in PDIV tests of insulated wires under repetitive impulse supply voltage. In Proceedings of the 2019 IEEE Electrical Insulation Conference (EIC), Calgary, AB, Canada, 16-19 June 2019; pp. 505-508.

190. Lusuardi, L.; Cavallini, A.; de la Calle, M.G.; Martínez-Tarifa, J.M.; Robles, G. Insulation design of low voltage electrical motors fed by PWM inverters. IEEE Electr. Insul. Mag. 2019, 35, 7-15. [CrossRef]

191. Lusuardi, L.; Cavallini, A.; Mancinelli, P.; Manuel, G.D.L.C.; Martínez-Tarifa, J.M.; Robles, G. Design criteria for inverter-fed Type 1 motors. In Proceedings of the 2016 IEEE International Conference on Dielectrics (ICD), Montpellier, France, 3-7 July 2016; pp. 605-608.

192. Lusuardi, L.; Cavallini, A.; Caprara, A.; Bardelli, F.; Cattazzo, A. The Impact of Test Voltage Waveform in Determining the Repetitive Partial Discharge Inception Voltage of Type I Turn/Turn Insulation Used in Inverter-Fed Induction Motors. In Proceedings of the 2018 IEEE Electrical Insulation Conference (EIC), San Antonio, TX, USA, 17-20 June 2018; pp. 478-481.

193. Hameyer, K.; Ruf, A.; Pauli, F. Influence of fast switching semiconductors on the winding insulation system of electrical machines. In Proceedings of the 2018 International Power Electronics Conference (IPEC Niigata 2018 ECCE Asia), Niigata, Japan, 20-24 May 2018; pp. 740-745.

194. Pauli, F.; Ruf, A.; Hameyer, K. Low voltage winding insulation systems under the influence of high du/dt slew rate inverter voltage. Arch. Electr. Eng. 2020, 69, 187-202. [CrossRef]

195. Driendl, N.; Pauli, F.; Hameyer, K. Modeling of Partial Discharge Processes in Winding Insulation of Low-Voltage Electrical Machines Supplied by High du/dt Inverters. In Proceedings of the IECON 2019—45th Annual Conference of the IEEE Industrial Electronics Society; IEEE, Lisbon, Portugal, 14-17 October 2019; pp. 7102-7107.

196. Hammarström, T.J.A. Differences in partial discharge characteristics due to increased conductivity of the insulation material. In Proceedings of the 2018 12th International Conference on the Properties and Applications of Dielectric Materials (ICPADM), Xi'an, China, 20-24 May 2018; pp. 148-151.

197. Hammarström, T.J.A.; Bengtsson, T.; Gubanski, S.M. Partial discharge characteristics in motor insulations under exposure to multi-level inverters. In Proceedings of the 2017 IEEE Conference on Electrical Insulation and Dielectric Phenomenon (CEIDP), Fort Worth, TX, USA, 22-25 October 2017; pp. 307-310.

198. Hammarström, T.J.A. Partial discharge characteristics within motor insulation exposed to multi-level PWM waveforms. IEEE Trans. Dielectr. Electr. Insul. 2018, 25, 559-567. [CrossRef]

199. Hammarström, T.J.A. The Implications on the PD Characteristics of Unipolar versus Bipolar PWM waveforms. In Proceedings of the 2019 IEEE Electrical Insulation Conference (EIC), Calgary, AB, Canada, 16-19 June 2019; pp. $42-45$.

200. Hammarström, T.J.A. Multilevel PWM: A Tool to Explore Insulation PD Characteristics. IEEE Trans. Instrum. Meas. 2019, 68, 4075-4084. [CrossRef]

201. Hammarström, T.J.A. A Measurement Set-Up Method to Evaluate Motor Winding Quality and Winding Insulation by Exploring Discharge Characteristics. In Proceedings of the 2018 21st International Conference on Electrical Machines and Systems (ICEMS), Jeju, Korea, 7-10 October 2018; pp. 678-683.

202. Hammarström, T.J.A. Multi-rise time PWM: A way to reduce PD exposure in motor windings. IEEE Trans. Dielectr. Electr. Insul. 2020, 27, 613-621. [CrossRef]

203. Wang, P.; Wang, J.; Xu, H.; Zhou, K.; Lei, Y.; Zhou, Q. Comparative study of PD characteristics for inverter-fed motor insulation under sinusoidal and repetitive square wave voltage conditions. In Proceedings of the 2016 IEEE International Conference on High Voltage Engineering and Application (ICHVE), Chengdu, China, 19-22 September 2016; pp. 1-4.

204. Wang, P.; Xu, H.; Wang, J.; Cavallini, A.; Montanari, G.C. Temperature effects on PD statistics and endurance of inverter-fed motor insulation under repetitive square wave voltages. In Proceedings of the 2016 IEEE Electrical Insulation Conference (EIC), Montreal, QC, Canada, 19-22 June 2016; pp. 202-205.

205. Wang, P.; Xu, H.; Wang, J.; Cavallini, A.; Montanari, G.C. The effects of asymmetry repetitive square wave voltages on PD statistics and endurance. In Proceedings of the 2016 IEEE International Conference on Dielectrics (ICD), Montpellier, France, 3-7 July 2016; pp. 693-696.

206. Wang, P.; Xu, H.; Wang, J.; Cavallini, A. The influence of repetitive square wave voltage duty cycle on partial discharge statistics and insulation endurance. In Proceedings of the 2016 International Conference on Condition Monitoring and Diagnosis (CMD), Xi'an, China, 25-28 September 2016; pp. 274-277.

207. Wang, P.; Xu, H.; Wang, J.; Zhou, W.; Cavallini, A. The influence of repetitive square wave voltage rise time on partial discharge inception voltage. In Proceedings of the 2016 IEEE Conference on Electrical Insulation and Dielectric Phenomena (CEIDP), Toronto, ON, Canada, 16-19 October 2016; pp. 759-762.

208. Wang, P.; Xu, H.; Wang, J.; Wang, W.; Cavallini, A. Effect of repetitive impulsive voltage duty cycle on partial discharge features and insulation endurance of enameled wires for inverter-fed low voltage machines. IEEE Trans. Dielectr. Electr. Insul. 2017, 24, 2123-2131. [CrossRef]

209. Wang, P.; Zheng, C.; Li, Y.; Lei, Y.; Cavallini, A. The PD and Endurance Features of Enameled Wires at Short Repetitive Impulsive Voltages. In Proceedings of the 2018 IEEE Electrical Insulation Conference (EIC), San Antonio, TX, USA, 17-20 June 2018; pp. 572-576. 
210. Wang, P.; Yang, N.; Zheng, C.; Li, Y. Effect of repetitive impulsive and square wave voltage frequency on partial discharge features. In Proceedings of the 2018 12th International Conference on the Properties and Applications of Dielectric Materials (ICPADM), Xi'an, China, 20-24 May 2018; pp. 152-155.

211. Wang, P.; Zhao, M.; Zhou, Q.; Zhang, J. The Influence of SPWM Frequency on the Endurance of Inverter-fed Motor Insulation. In Proceedings of the 2019 IEEE Conference on Electrical Insulation and Dielectric Phenomena (CEIDP), Richland, WA, USA, 20-23 October 2019; pp. 142-145.

212. Guastavino, F.; Cordano, D.; Torello, E.; Della Giovanna, L. PD evolution of conventional and corona resistant enamels. In Proceedings of the 2016 IEEE Conference on Electrical Insulation and Dielectric Phenomena (CEIDP), Toronto, ON, Canada, 16-19 October 2016; pp. 259-262.

213. Guastavino, F.; Rossi, F.; Gianoglio, C.; Torello, E.; Cordano, D. PDIV and RPDIV on different temperatures on different kind of type I insulating system. In Proceedings of the 2017 IEEE Conference on Electrical Insulation and Dielectric Phenomenon (CEIDP), Fort Worth, TX, USA, 22-25 October 2017; pp. 369-372.

214. Guastavino, F.; Gianoglio, C.; Torello, E.; Ferraris, M.; Gianelli, W. Behaviour of Conventional and Nanofilled Impregnation Resins when Subjected to PD Activity. In Proceedings of the 2018 IEEE 2nd International Conference on Dielectrics (ICD), Budapest, Hungary, 1-5 July 2018; pp. 1-3.

215. Lusuardi, L.; Rumi, A.; Cavallini, A.; Wang, P.; Han, T. Can Low Voltage Inverter-Fed Induction Motors Be Designed Allowing Partial Discharge Activity? In Proceedings of the 2019 IEEE Electrical Insulation Conference (EIC), Calgary, AB, Canada, 16-19 June 2019; pp. 79-82.

216. Dong, G.; Liu, T.; Zhang, M.; Li, Q.; Wang, Z. Effect of voltage waveform on partial discharge characteristics and insulation life. In Proceedings of the 2018 12th International Conference on the Properties and Applications of Dielectric Materials (ICPADM), Xi'an, China, 20-24 May 2018; pp. 144-147.

217. Benmamas, L.; Teste, P.; Krebs, G.; Odic, E.; Vangraefschepe, F.; Hamiti, T. Contribution to partial discharge analysis in inverter-fed motor windings for automotive application. In Proceedings of the 2017 IEEE Electrical Insulation Conference (EIC), Baltimore, MD, USA, 11-14 June 2017; pp. 348-351.

218. Akram, S.; Wang, P.; Nazir, M.T.; Zhou, K.; Bhutta, M.S.; Hussain, H. Impact of impulse voltage frequency on the partial discharge characteristic of electric vehicles motor insulation. Eng. Fail. Anal. 2020, 116, 104767. [CrossRef]

219. Frosini, L.; Zanazzo, S.; Albini, A.; Ferraris, M. An experimental investigation of the high frequency effects in low voltage electrical drives. In Proceedings of the 2017 IEEE 11th International Symposium on Diagnostics for Electrical Machines, Power Electronics and Drives (SDEMPED), Tinos, Greece, 29 August-1 September 2017; pp. 97-103.

220. Wei, Z.; You, H.; Hu, B.; Na, R.; Wang, J. Partial Discharge Behavior on Twisted Pair under Ultra-short Rise Time Square-wave Excitations. In Proceedings of the 2019 IEEE Electrical Insulation Conference (EIC), Calgary, AB, Canada, 16-19 June 2019; pp. 493-496.

221. Montanari, G.C.; Seri, P. The effect of inverter characteristics on partial discharge and life behavior of wire insulation. IEEE Electr. Insul. Mag. 2018, 34, 32-39. [CrossRef]

222. Florkowski, M.; Florkowska, B.; Zydron, P. Partial discharges in insulating systems of low voltage electric motors fed by power electronics-Twisted-pair samples evaluation. Energies. 2019, 12, 768. [CrossRef]

223. La Calle, M.G.D.; Martínez-Tarifa, J.M.; Solanilla, Á.M.G.; Robles, G. Uncertainty Sources in the Estimation of the Partial Discharge Inception Voltage in Turn-to-Turn Insulation Systems. IEEE Access. 2020, 8, 157510-157519. [CrossRef]

224. Rao, S.N.; Elanseralathan, K. Influence of PWM technique on breakdown in twisted pairs. In Proceedings of the $20173 \mathrm{rd}$ International Conference on Condition Assessment Techniques in Electrical Systems (CATCON), Rupnagar, India, 16-18 November 2017; pp. 427-431.

225. Rao, S.N.; Elanseralathan, K. Influence of switching frequency of the voltage waveforms on breakdown in twisted pairs. In Proceedings of the 2016 International Conference on Electrical Power and Energy Systems (ICEPES), Bhopal, India, 14-16 December 2016; pp. 545-548.

226. Elanseralathan, K.; Pravinraj, R. Effect of switching frequency on the breakdown of twisted pairs due to Power Electronic Converters. In Proceedings of the 2016 National Power Systems Conference (NPSC), Bhubaneswar, India, 19-21 December 2016; pp. $1-4$.

227. Leuzzi, R.; Monopoli, V.G.; Rovere, L.; Cupertino, F.; Zanchetta, P. Effects of Electrical Ageing on Winding Insulation in HighSpeed Motors: Analysis and Modelling. In Proceedings of the 2018 IEEE Energy Conversion Congress and Exposition (ECCE), Portland, OR, USA, 23-27 September 2018; pp. 6886-6892.

228. Leuzzi, R.; Monopoli, V.G.; Rovere, L.; Cupertino, F.; Zanchetta, P. Analysis and Detection of Electrical Aging Effects on High-Speed Motor Insulation. IEEE Trans. Ind. Appl. 2019, 55, 6018-6025. [CrossRef]

229. Leuzzi, R.; Monopoli, V.G.; Cupertino, F.; Zanchetta, P. Active Ageing Control of Winding Insulation in High Frequency Electric Drives. In Proceedings of the 2018 IEEE Energy Conversion Congress and Exposition (ECCE), Portland, OR, USA, 23-27 September 2018; pp. 1-7.

230. Florkowska, B.; Florkowski, M.; Zydroń, P.; Roehrich, J. Experimental evaluation of breakdown voltage and life time for models of the low voltage electrical motors windings. Przeglad Elektrotechniczny 2016, 92, 21-25. [CrossRef] 
231. Yuan, P.; Liu, X.; Lei, P.; Wang, J.; Fan, J.; Zhang, X.; Zhu, H. Deterioration of Stator Winding Insulation in Inverter-Fed Traction Motors. In Proceedings of the 2020 IEEE Electrical Insulation Conference (EIC), Knoxville, TN, USA, 22 June-3 July 2020 ; pp. 457-460.

232. Venugopal, G.; Gopalakrishnan, V.; Rajkumar, S.P. Identification of inter-turn insulation faults in induction motor. Eng. Comput. 2019. [CrossRef]

233. Ruf, A.; Paustenbach, J.; Franck, D.; Hameyer, K. A methodology to identify electrical ageing of winding insulation systems. In Proceedings of the 2017 IEEE International Electric Machines and Drives Conference (IEMDC), Miami, FL, USA, 21-24 May 2017; pp. 1-7.

234. Xie, Y.; Zhang, J.; Leonardi, F.; Munoz, A.R.; Degner, M.W.; Liang, F. Modeling and Verification of Electrical Stress in InverterDriven Electric Machine Windings. IEEE Trans. Ind. Appl. 2019, 55, 5818-5829. [CrossRef]

235. Xie, Y.; Zhang, J.; Leonardi, F.; Munoz, A.R.; Degner, M.W.; Komma, D. Voltage Propagation in Inverter-driven Machine Windings over Wide Operation Range. In Proceedings of the 2020 IEEE Transportation Electrification Conference \& Expo (ITEC), Chicago, IL, USA, 23-26 June 2020; pp. 1140-1146.

236. Xie, Y.; Zhang, J.; Leonardi, F.; Munoz, A.R.; Degner, M.W.; Liang, F. Voltage Stress Modeling and Measurement for RandomWound Windings Driven by Inverters. In Proceedings of the 2019 IEEE International Electric Machines \& Drives Conference (IEMDC), San Diego, CA, USA, 12-15 May 2019; pp. 1917-1924. 